\title{
Road
}

Materials ms

Pavement

Design
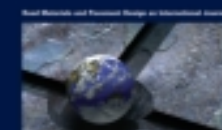

$\overline{1}$

On the Degree of binder Activity of reclaimed asphalt and Degree of Blending with recycling agents

\begin{tabular}{|r|l|}
\hline Journal: & Road Materials and Pavement Design \\
\hline Manuscript ID & RMPD-18-06-20.R1 \\
\hline Manuscript Type: & State of the Art \\
\hline Keywords: & $\begin{array}{l}\text { degree of activity, degree of blending, degree of availability, reclaimed } \\
\text { asphalt, recycling agent, recycled asphalt mixtures }\end{array}$ \\
\hline
\end{tabular}

\section{SCHOLARONE \\ Manuscripts}




\title{
On the Degree of binder Activity of reclaimed asphalt and Degree of Blending with recycling agents
}

\begin{abstract}
It's common practice to assume full blending of the aged binder of reclaimed asphalt (RA) within the design of new asphalt mixtures. Although being practical, this assumption has often led designers to asphalt mixtures lacking binder. Hence, going towards recycled asphalt mixtures (RAM) there is a need to have a better understanding of the blending phenomena, to have a general agreement on terminology and finally adapting RA classification and mix design procedures accordingly. This manuscript aims at being both a reference and stimulus for the scientific community to work in this direction and on this basis provides a nomenclature and a theoretical framework of the blending phenomena. The study is built upon a literature review on definitions, methods and influencing factors related with the blending phenomena and as a result an intrinsic property of RA, the degree of binder activity (DoA), is introduced for the sake of improving RA classification. Furthermore, the two well-known concepts of degree of Blending (DoB) and degree of Availability (DoAv) are redefined, within the proposed framework, together with practical suggestions to introduce them in mix design procedures.
\end{abstract}

Keywords: degree of activity; degree of blending; degree of availability; recycled asphalt; recycling agent, blending phenomena

\section{Introduction}

As road pavement engineering is making use of a life-cycle-based design approach, the implementation of End-of-life strategies for Reclaimed Asphalt (RA), such as road pavement asphalt mixtures with high RA content $(\geq 50 \%)$, is of paramount interest for road authorities and contractors (“AllBack2Pave," 2014; "COREPASOL," 2014; “DIRECT-MAT,” 2011; “EARN,” 2014; “Re-Road,” 2012; “SUP\&R ITN,” 2017). This growing popularity comes from the necessity to dismantle high amount of stock-piled material and to decrease/replace the use of finite resources, such as bituminous binder 
and virgin aggregates. Furthermore, the successful implementation of these technologies goes along the line of economic and environmental sustainability and these reasons are enough for the asphalt and road pavement industries to encourage the use of recycled asphalt mixtures (RAM), designed to minimise the amount of virgin materials and having recycling as default practices. Many limitations are still playing against the shift to RAM: lack of information about the long-term performance and durability; lack of guidelines/policies and road agency specifications for the production and quality control; technical issues related to the complexity of the formulation itself and to the capabilities of the asphalt plants. These reasons are at the base of the differences between the adoption in different EU countries and beyond. In fact, the amount of RA in asphalt layers is limited to $10-30 \%$ (Hungary, Sweden, Poland) or even prohibited in wearing courses (Czech Republic, Spain), while in others the RA can be used up to $100 \%$ (Germany, Norway, Denmark) (Mollenhauer et al., 2010; Partl et al., 2013).

In fact, in order to be considered as sustainable solutions, whether they are obtained with hot, warm, or half-warm process, the RAM with low-content of virgin materials should meet at least the same requirements valid for traditional mixtures (composed by all virgin materials or with low recycled content). However, RA is a complex material, which is different, especially in terms of variability, from the traditional components used in asphalt mixtures. RA is actually a family of materials that we are still studying and characterising to provide recommendations for their classification ((Tebaldi et al., 2018)) as well as for a more confident design and performance prediction of the resulting asphalt mixtures, especially for the RAM. Some of the aspects that play a fundamental role in this process are (Bressi et al., 2015; Copeland, 2011; Di Mino et al., 2015; Hossain, Musty, \& Sabahfer, 2012; Howard, 
Cooley, \& Doyle, 2009; Lo Presti et al., 2015; Newcomb, Ray Brown, \& Epps, 2007; Orešković, Bressi, Di Mino, \& Lo Presti, 2017; Partl et al., 2013):

- variability of RA properties due to the often-unknown nature and heterogeneity of RA,

- lack of specifications for the characterisation and classification of RA,

- lack of methods for accurately measuring the properties of the aged binder,

- uncertainties when polymers are incorporated,

- uncertainties in adapting existing mix design procedures,

- lack of fundamental understanding of some of the mechanisms involved during its mixing with the other components, such as recycling agents,

- lack of a widely accepted nomenclature to describe key quantities linked with the blending phenomena

With this in mind and with particular focus on the last two points, this paper provides the scientific community with a theoretical explanation and nomenclature of key mechanisms linked with the blending phenomena, together with a pragmatic framework to identify and possibly quantify two key properties. The first property is the minimum amount of aged binder available from a selected RA, here defined as the Degree of Binder Activity (DoA) and introduced to improve the classification of RA materials. The second, the Degree of Blending (DoB) between the aged asphalt binder coming from RA and the virgin binder and/or recycling agents, is here refined in light of literate review's findings and to serve for defining mix design procedures for RAM.

The next sections will first provide an overview of the literature review on the factors affecting the blending phenomena between RA and recycling agents, then the anticipated theoretical explanation and practical framework to assess DoA, DoAv and 
DoB will be followed by the conclusions and recommendations for the scientific community. For a detailed explanation of all the terms introduced and/or discussed in this work, a nomenclature section is provided at the end of the manuscript.

\section{State of the art: Degree of Blending and related factors}

It is well known that when a RA is incorporated within the manufacturing of asphalt mixtures, eventually with recycling agent, a portion of the aged binder surrounding the RA aggregates acts as a binder in the new formulation.

The quantity of RA binder in the asphalt mix is identified sometime as asphalt binder replacement, recycled binder ratio, effective RAP binder, RAP binder contribution, RAP binder activity, RAP working binder, RAP binder availability (Kaseer, Arámbula-Mercado, \& Martin, 2019), replaced virgin binder (Davide Lo Presti, Jimenez del Barco Carrion, Airey, \& Hajj, 2016) and amount of re-activated binder (Stimilli, Virgili, \& Canestrari, 2015). In mix design practices, this quantity is considered as a percentage of RA binder by weight with respect to the total binder by weight in the asphalt mixture, however its accurate estimation still raises concerns due to its ultimate effect on mxi performance. In fact, despite the current practices allow asphalt technologists to assess the binder content of RA, it is still not clear how much of this available binder will actually contribute to the properties of the asphalt mixtures incorporating RA. 


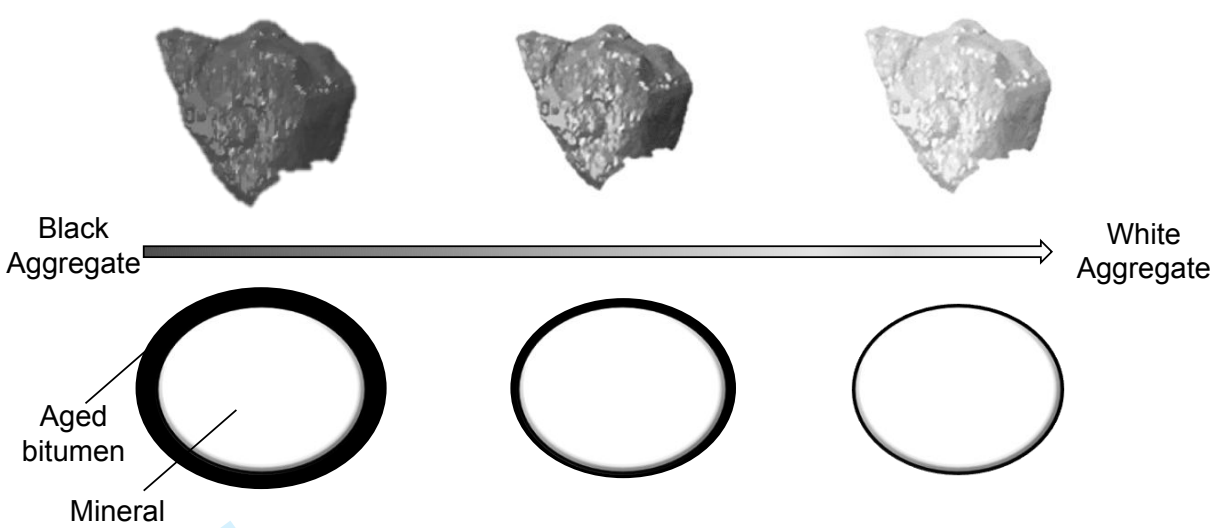

Figure 1. Full-Partial-Null availability concept

In this regard, asphalt technologists typically consider two opposite scenarios: "full availability" and "black rock" (Kaseer et al., 2019). Full availability (white aggregate in

Figure 1) assumes that $100 \%$ of the RA binder amount can be considered in the new mix design as part of the new binder blend. This is here defined as $100 \%$ available RA binder. "Black rock" states that $0 \%$ of the RA binder will be active and that the RA behaves as "black aggregate" (black aggregate in

Figure 1). However, it is a common belief that the RA binder does not act in the mixture just like a "black rock", and also that full activity might also possibly not happen. A more realistic hypothesis lies between these two extremes and it is usually described as "partial availability" concept (grey aggregate in

Figure 1). Despite this concept is well recognized, in practice within the mix design of asphalt mixtures incorporating RA is typical considering the RA binder fully active (AASTHO M323-12, 2012).

When discussing about the blending phenomena, it is important to distinguish between the amount of available RA binder as well as the efficiency of the blending with 
recycling agents. The first is linked to the degree of availability and to what here will be defined as "Degree of binder Activity (DoA)", and the second is what here is referred as "Degree of Blending (DoB)". This is necessary to consider since these quantities affects the mix design process differently: (i) Degree of Activity/Availability allow using a lower amount of virgin binder, when this is used as recycling agent; (ii) DoB allows estimating the contribution that RA binder and recycling agent have in the conventional/rheological properties of the final binder in the new asphalt mixture formulation. Hence, the first refers to an amount of RA binder that can be considered in mix design practices, as above mentioned, while the DoB indicates how well, in terms of binder and/or mixture properties, the RAP binder and recycling agents blends.

These concepts seem to be widely recognised by the scientific community, however the results of a literature review (Table 1) highlighted that practitioners have not yet achieved a general consensus on the terms related to the blending phenomena and authors use concepts and terms interchangeably. Amongst these: blending efficiency (Bowers, Huang, Shu, \& Miller, 2014; Bowers, Moore, Huang, \& Shu, 2014; Ding, Huang, \& Shu, 2016; Xu, Hao, Zhang, \& Yuan, 2018), blending status (Zhao, Huang, Shu, \& Woods, 2016), blending ratio (Delfosse, Drouadaine, Largeaud, \& Dumont, 2016), rate of intermixing (Oliver, 2001), binder transfer (Zhang, Wen, \& Hobbs, 2015), mobilization rate (Bressi et al., 2015; Ding, Huang, \& Shu, 2018; Vassaux et al., 2018; Zhao, Huang, Shu, \& Woods, 2015), meso-blending (Gundla \& Underwood, 2015) and the most used terminology by far degree of blending (DoB) (Abd, Al-Khalid, \& Akhtar, 2018; Al-Qadi et al., 2009; Booshehrian, Mogawer, \& Bonaquist, 2013; Castorena, Pape, \& Mooney, 2016; Cavalli, Partl, \& Poulikakos, 2017; Coffey, Dubois, Mehta, \& Purdy, 2013; Gaitan et al., 2013; Kriz et al., 2014; Liphardt, Radziszewski, \& Król, 2015; Mogawer, Booshehrian, Vahidi, \& Austerman, 2013; Mogawer et al., 2012; Navaro et 
al., 2012; Norton et al., 2014; Rinaldini, Schuetz, Partl, Tebaldi, \& Poulikakos, 2014; Shirodkar et al., 2013, 2011; Stephens, Mahoney, \& Dippold, 2001).

Table 1. Definitions of terms related to the blending phenomena as found in literature Reference Definition

(Shirodkar et al., 2011) The degree of blending presents the amount of RAP binder that will be available for blending with virgin binder.

(Coffey, Dubois, Mehta, The degree of blending is the percentage of RA binder Nolan, \& Purdy, 2013; that is effectively mobilized within the mix.

Coffey, Dubois, Mehta, \&

Purdy, 2013; Shirodkar et al., 2013)

(Norton et al., 2014)

The amount of residual binder that is active in a mix is known as degree of blending.

(Stimilli et al., 2015)

Re-activated binder represents a partially melted aged binder that coats the RAP fraction and interacts with the virgin binder contributing to the overall performance of the resulting RMA.

(Gundla \& Underwood, Meso-blending refers to the blending of asphalt at 2015) scales above the micro- or molecular levels. It is less concerned with homogenization of the molecular constituents and more-so with the formation of a third binding material that may be considered homogeneous 
at the scale wherein rheological properties manifest (millimeters and smaller). It is at this scale that the asphalt binder imparts its rheological characteristics to the mixture.

(Ashtiani, Mogawer, \& Binder contribution describes the quantity of asphalt Austerman, 2018) binder from RAP that participates as effective binder in a mixture design.

(Vassaux et al., 2018) The remobilization represents the ability for the virgin binder to make mobile again and disperse the RA aged binder layer.

(Gottumukkala, $\mathrm{Ph}$, Kusam, Blending ratio is defined as the ratio of the weight of Tandon, \& Asce, 2018) RAP binder blending with virgin binder to the total weight of RAP binder.

(Ding et al., 2018) The mobilization rate is defined as the percentage of RA binder that can be mobilized during mixing, peeled off RA aggregate and made available for blending with recycling agents.

(Vassaux et al., 2019) "Blend" presents the ability of two components to create a homogenous product where the chemical composition is identical everywhere at the scale observation of the study.

These definitions create confusion and overlapping which ultimately result in communication issues amongst practitioners, but it also highlights the lack of a general consensus on the theoretical mechanisms linked with the blending phenomena. This is 
also due to the fact that the phenomenon occurring when a selected RA is heated and blended with a recycling agent is quite complex and several factors influence the outcome. In order to clarify this key aspect, a literature review has also been undertaken to identify the factors that the scientific community recognises having an influence on the RA binder blending phenomena. Table 2 and Table 3 show the results for each parameter and the explanation of the role played within the blending phenomenon. Furthermore, analysing the many factors identified, it was recognised that some are linked to the design and manufacturing of the asphalt mixture containing RA (Table 2), while some others are strictly related to the RA (Table 3 ).

Table 2. Influencing factors on the DoB: Design and manufacturing of asphalt mixture containing RA

\begin{tabular}{l|l}
\hline Parameters & Explanation of the influence (or not) on DoB, and reference \\
\hline Mixing temperature & $\begin{array}{l}\text { If mixing temperature is high enough, the RA binder should } \\
\text { become softer, or even fluid, making it available for blending } \\
\text { (Bowers, Moore, et al., 2014; Campher, 2012; Cavalli et al., } \\
2017 ; \text { Ding, Huang, Shu, Zhang, \& Woods, 2016; He, Alavi, } \\
\text { Harvey, \& Jones, 2016; Kaseer, Arámbula-Mercado, \& Martin, } \\
2019 ; \text { Kriz et al., 2014; Lo Presti et al., 2015; Nahar et al., 2013; } \\
\text { Navaro et al., 2012; Oliver, 2001; Rad, Sefidmazgi, \& Bahia, } \\
2014 ; \text { Stephens et al., 2001; Zhang et al., 2015; Zhao et al., } \\
2015) . \\
\text { Only one research study showed that mixing temperature seems } \\
\text { not to influence the DoB (Gaitan et al., 2013). }\end{array}$
\end{tabular}


Conditioning time

Mixing time

Content of RA in a new mixture

Virgin aggregate shape
If the conditioning time is prolonged enough, the blending process may resulted in increased blending of the virgin and the RA binder (He et al., 2016; Kaseer et al., 2019; Rad et al., 2014) .

If the mixing time is prolonged, it can be possible that RA particles began to interact with each other increasing the amount of the available RA binder (Bowers, Moore, et al., 2014; Gaitan et al., 2013; Nahar et al., 2013; Navaro et al., 2012; Oliver, 2001; Rad et al., 2014; Zhang et al., 2015; Zhao et al., 2016).

Only one research study showed that this is not the case (Stephens et al., 2001).

Several studies showed that if the RA content is too high, more energy would be required to activate the RA binder (Booshehrian et al., 2013; Gottumukkala et al., 2018; Huang, Pauli, Grimes, \& Turner, 2014; Kriz et al., 2014; McDaniel, Soleymani, Anderson, Turner, \& Peterson, 2000; Oliver, 2001; Shirodkar et al., 2011; Stimilli et al., 2015; Zhang et al., 2015; Zhao et al., 2015).

However, one study showed that RA content does not influence the amount of active binder (B. Huang, Li, Vukosavljevic, Shu, \& Egan, 2005).

When virgin aggregate grains have high angularity, it will be 
Binder additives and admixtures

Virgin binder properties

Filler particles

Aggregate absorption

Mixture reheating easier to release the aged binder from the RA particles compared to more rounded aggregate (Zhao et al., 2015).

Recycling agents, anti-stripping agents or other additives may be mixed with the RA or added to the virgin binder with the aim to soften or activate the RA binder (Bowers, Moore, et al., 2014; Gaitan et al., 2013; Kaseer et al., 2019; Liphardt et al., 2015; Mogawer et al., 2013)

If the virgin binder has lower viscosity, it will easily cover RA particles and improve the DoB (Booshehrian et al., 2013; Gottumukkala et al., 2018; Hofko et al., 2016; Nahar et al., 2013; Norton et al., 2014; Rad et al., 2014; Shirodkar et al., 2013, 2011).

This does not seem the case for the research study conducted by Huang et al. (2014).

High amount of filler particles will absorb a recycling agent before it covers RA and starts with softening of the available recycled aged binder (Al-Qadi et al., 2009; Stimilli et al., 2015)

Aggregate with high porosity will absorb a recycling agent decreasing the active amount of recycling agent that is considered during mix design phase (Al-Qadi et al., 2009).

Successive heating of asphalt mixtures containing RA can increase the diffusion process improving the DoB (Booshehrian 


\begin{tabular}{l|l} 
Surface texture of virgin & $\begin{array}{l}\text { et al., 2013). } \\
\text { Recycling agent can fulfil convex parts of the grains before } \\
\text { aggregate }\end{array}$ \\
blending with the RA binder decreasing the designed amount \\
of a recycling agent (Cavalli et al., 2016, 2017). \\
Virgin aggregate (type,
\end{tabular}

Table 3. Influencing factors on the DoB: RA characteristics

\begin{tabular}{l|l}
\hline Parameters & Explanation of the influence (or not) on DoB, and reference \\
\hline RA Conditioning time / & $\begin{array}{l}\text { Conditioning the RA for prolonged time, at high operative } \\
\text { temperatures seems to be beneficial for softening the RA binder } \\
\text { (He et al., 2016; Rad et al., 2014). } \\
\text { One research study showed that this is not the case (Gaitan et } \\
\text { al., 2013). } \\
\text { With the increase of the RA binder stiffness, it will be more } \\
\text { difficult to increase the DoB (Booshehrian et al., 2013; Hofko } \\
\text { et al., 2016; Kaseer et al., 2019; Nahar et al., 2013; Norton et } \\
\text { al., 2014; Rad et al., 2014; Shirodkar et al., 2013, 2011). } \\
\text { This does not seem the case for one research studies (S.-C. } \\
\text { Huang et al., 2014). }\end{array}$
\end{tabular}


RA binder film thickness

RA fraction size

RA Variability

Moisture content of RA
As much as the RA binder film is thicker, there will be more binder which may be activated and blended during the mixing phase increasing the DoB (Cavalli et al., 2016, 2017; Kriz et al., 2014; Liphardt et al., 2015; Stimilli et al., 2015).

Due to increase of the specific surface area with reduction in the size of RA particles, the amount of aged binder will be higher implying more binder available for blending (Castorena et al., 2016; Ding, Huang, \& Shu, 2016; Stephens et al., 2001; Stimilli et al., 2015).

However, this does not seem the case for Shirodkar et al. (2011)

High RA variability can contribute an unequal distribution of both RA binder and aggregated causing various DoB within an asphalt mixture (Cavalli et al., 2016; Norton et al., 2014).

Since the mixing time is limited during asphalt production phase, heating of the RA with high moisture content will firstly cause the release of water, not softening of the RA binder (Campher, 2012; Zhang et al., 2015).

Surface texture and the

If the RA aggregate is geometrically inhomogeneous, the RA binder will be trapped in convex parts of grains and possible micro geometrical would not be able to be released during mixing phase (Cavalli inhomogeneity of RA aggregate et al., 2016, 2017) 


\subsection{The need for the Degree of binder Activity (DoA)}

From a careful analysis of the findings reported in Tables 1-3, it is possible to highlight that the blending phenomena is certainly influenced by the selected pre-processing conditions of the RA: mixing temperature and time, RA content, RA type and applied recycling agent. In all the studies found in literature, the blending phenomena has always been studied in a scenario where the RA is blended with a recycling agent (hereinafter referred to as "RA + recycling agent scenario"). This is certainly the most common scenario possible in practice, if not the only so far, however the "only-RA scenario" deserves to be considered, especially in the classification of the RA. Furthermore, Table 3 shows that the amount of RA binder made available/active may vary regardless of the addition of the recycling agents. Hence, for the sake of improving RA characterisation and classification, as well as to perform more informed design procedure for RAM, the authors believe, that the concepts of RA binder availability and DoB must also be linked to an intrinsic property of the RA only and introduce the Degree of binder Activity (DoA) here defined as "the minimum amount of active $R A$ binder that a designer can consider for a selected RA and a selected asphalt manufacturing process". This is deemed necessary since DoA is an intrinsic property of RA that it is not related to the presence of recycling agents and it changes by varying RA type and processing conditions (i.e time, temperature).

\section{Theoretical framework of the blending phenomena}

In this section a theoretical framework of the blending phenomena will be firstly explored. The framework identifies quantities whose preliminary determination is fundamental for mix designers. Key mechanisms and relative definitions, and, when 
possible, formulations of DoA, DoAv and DoB, are provided to stimulate the scientific community in performing further research towards its validation as well as towards the definitions of methodologies to assess the identified key quantities.

\subsection{Key mechanisms for aged binder activity and blending}

A main assumption of the presented framework is that the presence of a recycling agent significantly affects the blending phenomena and the relative quantities. Hence the framework is here discussed within two scenarios: "Only-RA" and "RA + recycling agent”.

"Only-RA“ scenario: The aged binder is presented in two different phases in the RA, as: available and unavailable (Figure 2). When only RA is considered in the system, the available RA binder is equal to the active binder and represents the minimum amount of aged binder, that at certain processing conditions (mixing temperature $\mathrm{T}$, and time $\mathrm{t}$ ) can be considered available/active in the formulation of recycled asphalt mixtures. It consists of two components, and both together represent the active/available binder (Equation 1):

$W_{\text {activeRAb }}($ RA type, $\mathrm{t}, \mathrm{T})=W_{\text {liquidRAb }}+W_{\text {softerRAb }}[g]$ Equation 1

where $W_{\text {liquidRAb }}$ presents the portion of the liquid RA binder that moves from the RA particle to other RA particles, or virgin aggregates, and $W_{\text {softerRAb }}$ presents the layer of aged binder that does not move from the RA particles, but becomes softer and acts as a glue.

On the other hand, the amount of aged binder that cannot be considered available in a new formulation is defined as the unavailable/inactive binder (Figure 2). This quantity is made of two components: 
- Black rock RA binder - the amount of aged binder which has become so stiff and brittle that is considered as part of the RA aggregate, showing no change in physical-chemical behaviour and properties of itself.

- Absorbed RA binder - the amount of aged binder that is absorbed by RA aggregate and is not considered effective as a binder film.

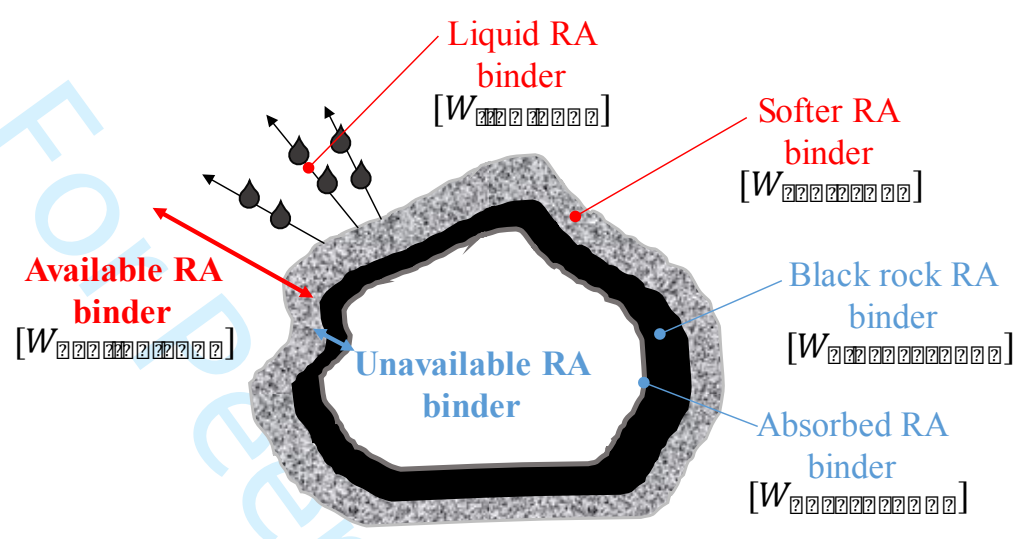

Figure 2. Example of the RA binder components

Hence, within the system with only RA, the total amount of RA binder $\left(W_{R A b, t o t a l}\right.$ ) and available ( $\left.\mathrm{W}_{\text {availableRAb }}\right)$ aged binder for a new formulation are given by Equations 2 and 3:

$W_{R A b, t o t a l}=W_{\text {active }}+W_{\text {inactive }}=W_{\text {liquidRAb }}+W_{\text {softerRAb }}+W_{\text {blackrockRAb }}+W_{\text {absorbedRAb }}[g]$ Equation 2

$W_{\text {availableRAb }}($ "only $R A-$ scenario" $)=W_{\text {activerAb }}($ RA type, $\mathrm{t}, \mathrm{T})[\mathrm{g}]$ Equation 3 where $W_{\text {liquidRAb }}$ is the amount of liquid RA binder [g], $W_{\text {softerRAb }}$ is the amount of softer RA binder [g], $W_{\text {blackrockRAb }}$ is the amount of black rock RA binder [g] and $W_{\text {absorbedRAb }}$ is the amount of absorbed RA binder $[\mathrm{g}]$.

„RA + recycling agent" scenario: Recycling agents are here defined as the family of additives/admixtures that are added within the recycled asphalt mixture manufacturing process with two different purposes: 1) "Rejuvenators" restore the 
properties of the aged RA binder (i.e. neat binder, naphthenic oils, etc.) to a desirable level and 2) "Lubricants" facilitate the mixing production process by allowing lower manufacturing temperatures, hence higher RA content (i.e. warm mix technologies). When any of these recycling agents is added to the mixture, the available and unavailable binder amounts may change due to further activitys which are proportional to the efficiency of the combination of the processing conditions and the recycling agent, as follow:

- Short-term activated binder (STAb): short term activity happens when the recycling agent gets in contact with aged binder at fixed processing conditions and it results in a decrease of the Black Rock and possibly Absorbed binder.

- Long-term activated binder (LTAb): long term activity is due to an eventual diffusion of the recycling agent into the RA binder over time. It might result in an even bigger decrease of the unavailable RA binder.

The activation of a certain amount of black rock RA binder and absorbed RA binder due to the effect of recycling agent, time and temperature forms the activated binder which is here defined:

$W_{\text {activatedRAb }}\left(\right.$ Rec.ag. type, RA type, t, T) $=W_{S T A b}+W_{L T A b}[g]$ Equation 4

Figure 3 clearly shows the difference between the 'active' RA binder („,Only-RA“ scenario) and the 'activated' binder (,RA + recycling agent" scenario). 


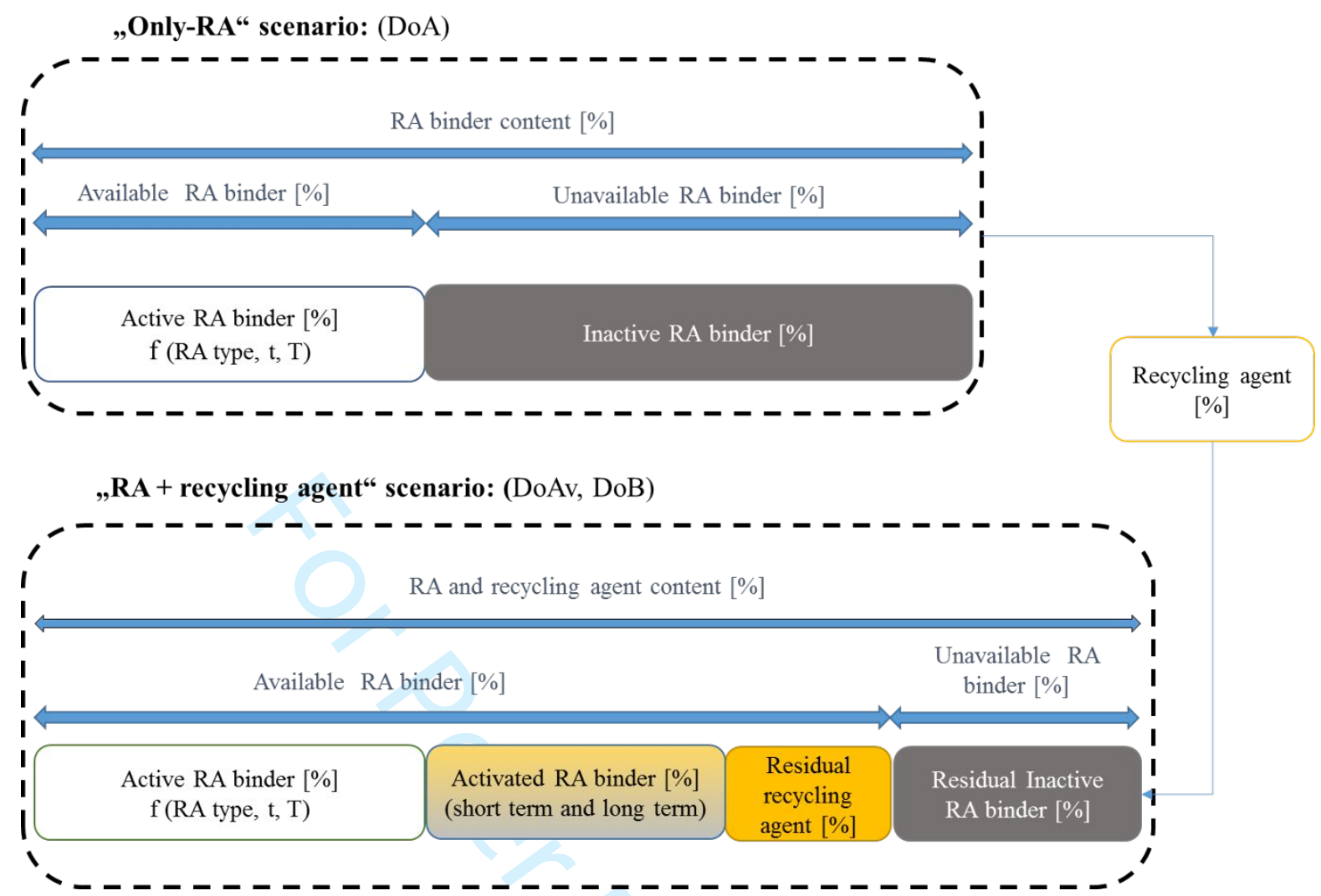

Figure 3. Schematic representation of the theoretical framework of the blending phenomena

As a result, in the presence of a recycling agent, the key mechanisms of the "onlyRA" scenario will change. If the recycling agent is effective in activating a portion of inactive aged binder, the available binder phase will increase due to the short-term and long-term activations (activated binder) as it is shown in Figure 3. Hence, the Inactive RA binder can be defined as the amount of aged binder that can only be partially activated by the combined effect of time, temperature and a recycling agent. Also, the total amount of binder within this scenario $\left(W_{\text {total }}\right)$, as in Eq. 5 , will increase exactly by the amount of recycling agent that will contribute forming the activated binder and will possibly stay in the blend as a residual component ( $W_{\text {resid.rec.ag. }}$ ). Equation 6 presents the formulation of the available amount of binder, considering the intrinsic characteristics of the RA, and also the recycling agent effect. 


$$
\begin{array}{lc}
W_{\text {total }}=W_{\text {liquidRAb }}+W_{\text {softerRAb }}+W_{S T A b}+W_{\text {LTAb }}+W_{\text {blackrock }}+W_{\text {absorbed }}+W_{\text {resid.rec.ag }}[g] & \text { Equation } 5 \\
W_{\text {availableRAb }}(R A+\text { rec.ag. })=W_{\text {activeRAb }}(\mathrm{RA} \text { type, } \mathrm{t}, \mathrm{T})+W_{\text {activatedRAb }}(\text { Rec.ag. type, RA type, } \mathrm{t}, \mathrm{T})[g] & \text { Equation } 6
\end{array}
$$

where $W_{S T A b}$ is the amount of short term activated RA binder [g], $W_{L T A b}$ is the amount of long term activated RA binder $[\mathrm{g}], W_{\text {blackrockRAb }}$ is the amount of black rock RA binder [g], $W_{\text {absorbedRAb }}$ is the amount of absorbed RA binder [g] and $W_{\text {resid.rec.ag. }}$ is the amount of a residual recycling agent $[\mathrm{g}]$.

\subsection{Degree of binder Activity (DoA)}

On the basis of the presented framework, the "Degree of binder Activity" (DoA) can be defined as the ratio between the minimum amount of aged binder that can be considered active for the formulation of the new recycled asphalt mixes (active binder) and the total aged asphalt binder. Hence, DoA is here considered to be an intrinsic property of each RA material and it will vary by changing the RA type and processing conditions (i.e. mixing temperature and time), regardless of the addition of recycling agents before and/or during the recycled asphalt mixture manufacturing. The activity is intended to characterize the minimum amount of aged binder that can be considered available in the new RA mixtures, hence it does not need replacing by a recycling agent. The DoA can be expressed as following:

$$
\begin{array}{ll}
D o A=\frac{W_{\text {active } A A b}(\text { RA type, } \mathrm{t}, \mathrm{T})}{W_{\text {RAb,total }}} \cdot 100[\% \text { mass }] & \text { Equation } 7
\end{array}
$$

where $W_{\text {active } A \text { Ab }}$ is the amount of active RA binder with no influence of recycling agent ( $W_{\text {liquidRAb }}$, and $W_{\text {softerRAb }}$ binders) $[\mathrm{g}]$, and $W_{R A b, t o t a l}$ is the total amount of binder in RA [g] according to binder extraction standards (ASTM 2172 - 17, 2017; EN 12697- 
$1: 2012,2012)$. The definition of the DoA is deemed as a necessary quantity to improve the classification the RA materials family, with regards to its use in half-warm - hot manufacturing of asphalt mixture. On this basis, the Task Group "DoA" of the RILEM Technical Committee 264 RAP is currently undertaking an inter-laboratory exercise to provide asphalt technologists with a procedures to assess it (Davide Lo Presti et al., 2017; Tebaldi \& Dave, 2015).

\subsection{Degree of binder Availability (DoAv)}

Within the only-RA scenario the available binder is equal to the active binder, hence there is no need to specify any other quantity. However when a recycling agent is added the amount of binder made available for mix design purposes is believed to change and the extent of change depends on the properties of both the aged binder and the recycling agent, as well as on a series of factors as described in Tables $2-3$. Hence, the available binder is believed to be formed by the active binder complemented by the activated binder and the residual amount of recycling agent (Fig.3). Hence, the degree of binder availability (DoAv) will probably be higher than the DoA and his estimation could be forecasted as follow:

$D o A v=\frac{W_{\text {availableRAb }}(R A+\text { rec.ag. })}{W_{R A b, t o t a l}} \cdot 100[\%$ mass $]$

Equation 8

Assuming the correct DoA/DoAv for a selected RA is crucial to obtain asphalt mixtures complying with specific design standards. In fact, mix design methodologies typically aim at estimating the optimum binder content of a given asphalt mixture, hence the risk is to under or over dosing asphalt binder for the recycled asphalt mixtures. This will provide high-content RA asphalt mixtures with lower performance than traditional ones (Coffey, Dubois, Mehta, Nolan, et al., 2013), and in turns it will affect the pavement 
design and durability (Norton et al., 2014, Kaseer et al., 2019). It needs to be underlined that activated RA is defined as the sum of a component immediately available during asphalt manufacturing (STAb) and a component that will be activated through diffusion (LTAb). Asphalt technologists might need to consider these difference within the design of asphalt mixture incorporating RA, since these components might be available a different stages and ageing might have a role in this picture.

\section{4. $\quad$ Towards a formulation for the Degree of Blending (DoB)}

The presence of a recycling agent will not change the active binder but will most likely change the available binder of a selected RA. The extent of this effect will in turn significantly affect the conventional/rheological properties of the final binder and/or asphalt mixture. Hence, this study wants to clearly separate definitions and proposes that "Degree of binder Blending (DoB)" could be defined as: an indicator describing to what extent the aged RA binder contributes to the final properties of the asphalt mixture's binder blend composed of aged binder and recycling agent.

This definition allows to focus the attention of the blending efficiency on the properties of the final blend rather that the amount of binder. Although this is fundamental to adapt mix design procedure, formulating the DoB hinders several issues, such as the uncertainty in selecting the property of the binder/mixture and the hypothesis of fullpartial-null blending.

Table 4. Proposed formulas for determination of the DoB from investigated literature Reference Formula

(Shirodkar et al., Blending ratio $=\frac{\mid A\left(\text { virgin }_{\text {agg }}\right)_{\text {blend binder }}-A\left(R A P_{\text {agg }}\right)_{\text {blend binder }} \mid}{\left|A_{\text {virg gin binder }}-A_{\text {RAP virgin binder oblend }}\right|}$ Equation 9 
2011)

where $A\left(\text { virgin }_{\text {agg }}\right)_{\text {blend binder }}$ is binder property " $\mathrm{A}$ " of blended binder coating the virgin aggregate, $A\left(R A P_{\text {agg }}\right)_{\text {blend binder }}$ is binder property " $\mathrm{A}$ " of binder blend coating the RAP aggregate, $A_{\text {virgin binder }}$ binder property "A" of virgin binder and $A_{R A P}$ virgin binder 0 blend is binder property " $\mathrm{A}$ " of the $\mathrm{RA}$ and virgin binder that is coating the RA aggregate assuming $0 \%$ blending.

Degree of parital blending $(\%)=100 \mid 1-$ Blending ratio $\mid$ Equation 10

(Bowers, Moore, Blending ratio $=\frac{\text { Coarse } L M S \%}{\text { Fine } L M S \%}$

Equation 11

et al., 2014)

where Coarse LMS\% presents the LMS\% of the coarse aggregate and Fine LMS\% presents the LMS\% of fine aggregate. LMS $\%$ is defined by the area beneath the chromatogram obtained by using Gel Permeation Chromatography (GPC). When dividing the chromatogram into 13 slices, the first 5 are considered the LMS and can be expressed as following:

$L M S \%=\frac{\text { Area of first } \frac{5}{13} \text { of chromatogram }}{\text { Total Ared beneath chromatogram }} \times 100 \quad$ Equation 12

(Kaseer, Garcia $P G H_{\text {blend }}=\left(R A P_{B R} \times P G H_{R A P}\right)+\left(R A S_{B R} \times P G H_{R A S}\right)+\left(B_{B R} \times\right.$

Cucalon, $\left.P G H_{\text {Base }}\right)$ Equation 13

Arambula- $\quad$ where $\mathrm{PGH}_{\text {blend }}$ is the high $\mathrm{PG}$ temperature of binder blend, $\mathrm{RAP}_{\mathrm{BR}}$ Mercado, Epps is RA binder ratio, $\mathrm{PGH}_{\mathrm{RAP}}$ is high $\mathrm{PG}$ temperature of RA binder, Martin, \& Epps, $\mathrm{RAS}_{\mathrm{BR}}$ is RAS ratio (if used), $\mathrm{PGH}_{\mathrm{RAS}}$ is high $\mathrm{PG}$ temperature of 2018) RAS (if used), $\mathrm{B}_{\mathrm{BR}}$ is virgin binder ratio and $\mathrm{PGH}_{\mathrm{Base}}$ is high $\mathrm{PG}$ temperature of virgin binder. 
(Yu, Shen, Zhang,

$B R=\frac{\ln \left(R_{c}^{\prime}\right)-\ln \left(R_{v}\right)}{\ln \left(R_{p}\right)-\ln \left(R_{v}\right)} \times 100 \%$

Equation 14

Zhang, \& Jia,

Where BR presents the RAP blending ratio, $R_{c}^{\prime}$ presents specific

2017; Shuai Yu,

Shen, Zhou, \& Li,

property parameters for a coarse-mixture binder, $R_{v}$ is specific

binder property parameters for the virgin binder and $R_{p}$ is specific binder property parameters for the proportion binder.

(Abed, Thom, \&

$D o B \%=\frac{I T S M_{A C-50 \% R A P}}{I T S M_{\text {control }}} \times 100 \%$

Equation 15

Lo Presti, 2018)

Where $\mathrm{DoB} \%$ is the percentage of the degree of blending between RAP and soft binders, ITSM $A C-50 \% R A P$ is the stiffness modulus of AC samples with $50 \%$ of RAP and ITSM $M_{\text {control }}$ is the stiffness of the control mixture.

Table 4 reports the most recent formulations of DoB from the literature and from a careful analysis can be seen that approaches are quite different and most of them were focused at the binder level by measuring rheological, mechanical and chemical properties. Analyses on binder requires binder extraction which may give inaccurate results, since they neglect the influence of the solvent used for extraction of aged binder. Furthermore, some of them force blending between a recycling agent and aged binder which may also cause inaccurate results.

Due to this complexity, the identification of a formula to describe the DoB is not included in this study. It is the hope of the authors that further research could make use of the provided theoretical framework of the blending phenomena and come up with appropriate formulations. Conventional/rheological/chemical properties of the RA binders, as well as the link with DoA/DoAv, should be considered in a possible 
formulation of the DoB. Also, these further studies should not be restricted to binders only and include testing of the RA, mastics/mortars and mixtures.

\section{5. $\quad$ Introducing DoB in mix design procedures}

In the era of performance-based design, considering the properties of the final blend as a target is of paramount importance. In fact, for the same reasons, AASHTO specification (AASTHO M323-12, 2012) prescribes that if less than 15\% RA is used, there should be no change in the virgin binder grade. Furthermore, if RA content is between $15 \%$ and $25 \%$, one grade softer virgin binder should be used, while if more than $25 \%$ RA is added to the mixture, blending charts should be used (Soleymani, Bahia, \& Bergan, 1999). Figure 4 is an example of blending charts, which helps determining the amount of RA that should satisfy certain binder properties, in this case high PG temperature that was defined as $\mathrm{T}_{\text {critical }}$ Linking the DoB to the final binder blend properties seems therefore fundamental, but it is not yet established which properties should be considered.

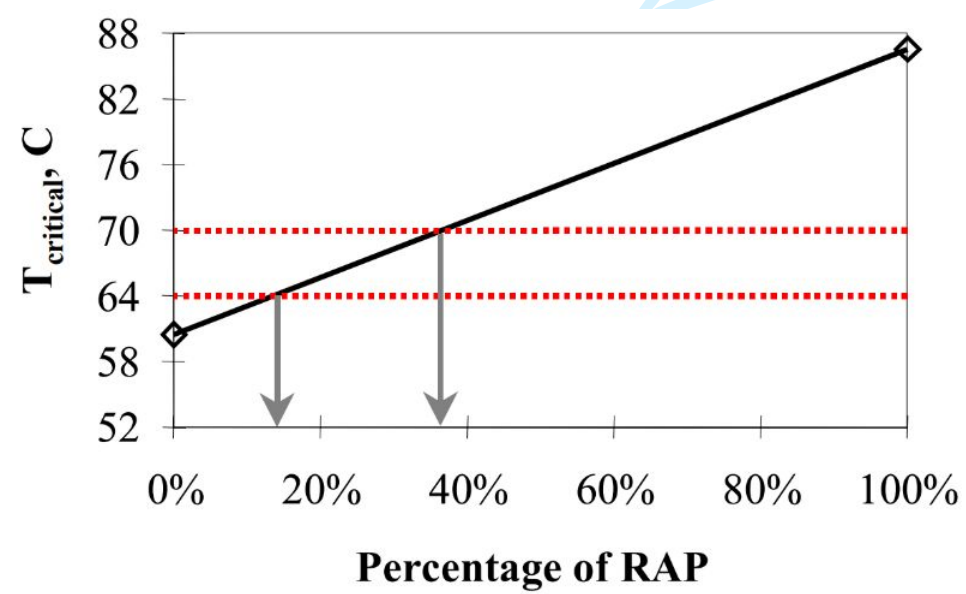

Figure 4. Blending chart and predicted law based on high PG temperature, adapted from McDaniel et al. (2000)

Another important remark towards the formulation of DoB is that this quantity should be lined with the previously defined DoA/DoAv. In fact, the final properties 
(mechanical, chemical, physical) of a binder blend may be correctly predicted by using blending charts, only if they are linked with the real amount of active/available binder from the RA and, eventually, recycling agent. In support of this, a previous study has shown that linear blending charts have limitations when high percentages of RA are used ( $>25 \%$ ) (Shirodkar et al., 2013). It was concluded that the blending charts proposed by AASHTO M 323-12 assumes that the properties binder blend changes linearly as the percentage of RA increases, but it is not certain whether this will be the case due to the uncertainty in the amount of binder "supplied" by the RA.

Al-Qadi, Elseifi, \& Carpenter (2007), Hajj et al. (2012) and Stephens et al. (2001) came out with the similar conclusion that blending charts, which are based on the assumption of full blending may be invalid if virgin and RA binder do not interact.

Since the full blending scenario does not necessarily mean that the whole amount of aged binder is blended with the recycling agent, the use of some blending charts may wrongly predict properties of final binder blend. With the aim to overcome this issue Jiménez del Barco Carrión, Lo Presti, \& Airey, (2015) suggested modifying the mix design methodologies by adapting the calculation of the replaced virgin binder (RVB) considering the uncertainty of the DoB:

$R V B(\%)=100 \cdot \frac{R A \text { content in the mixture } \cdot \text { Do } B \cdot R A \text { binder content }}{\text { binder content in the mixture }}$ Equation 16

where ' $R A$ content in the mixture' is total RA percentage to add in the mixture by weight, 'RA binder content' is the RA binder content, 'binder content in the mixture' is the designed final binder content in the mixture, ' $D o B$ ' is the assumed degree of blending between RA and virgin binder (Lo Presti et al., 2016). 
According to these studies, results allow mix designer to verify whether the quality of the selected recycling agents are suitable to obtain a final binder blend achieving the desired properties taking into account the effect of the DoB. On the basis of these evidences and keeping in mind that current practices consider mostly the "full blending" approach, it is important to here re-define the full-partial-null blending concept including the link between DoA, DoAv and DoB (

Figure 5c):

- $\mathrm{DoB}=0 \%$ or null blending is possible only when the RA binder is not active $(\mathrm{DoA}=\mathrm{DoAv}=0 \%)$, so there is no RA asphalt binder available to modify the physical/mechanical properties of final binder blend/mixture (

- Figure 5a).

- $0 \%<\mathrm{DoB}<100 \%$ or partial blending presents the case when only a certain amount of RA binder is activated within asphalt mixture $(0 \%<\mathrm{DoA}<$ DoAv $<100 \%$ ), hence it only partially contributes to the change in properties of final binder blend/mixture (

- Figure 5b).

- $\mathrm{DoB}=100 \%$ or full blending is an ideal scenario where the amount of RA binder engaged blends perfectly with the recycling agents, hence the final binder blend/mixture properties are proportional to the amount of RA binder content over the total binder amount in the mixture. It is important to underline that a full blending scenario could happen also without a full availability scenario $(0 \%<\operatorname{DoA} \prec \operatorname{DoAv}<100 \%)$. 


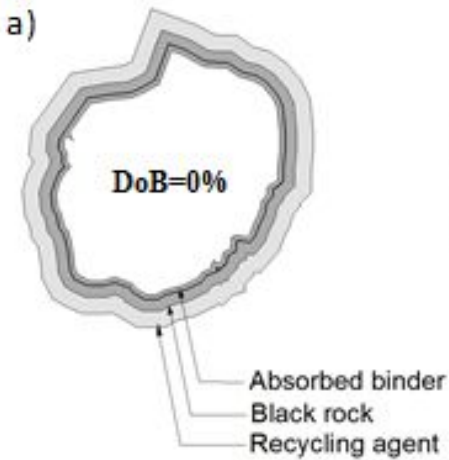

a) $\mathrm{DoA}=\mathrm{DoAv}=0 \%$

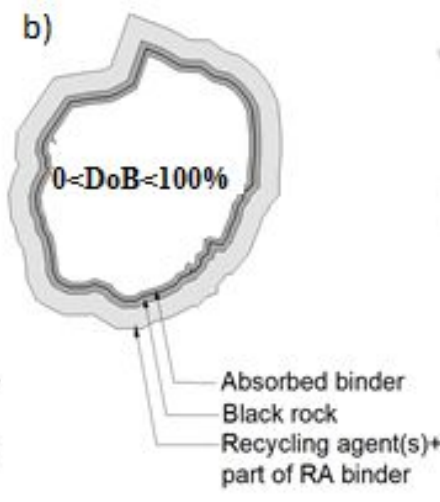

b) $\quad 0 \%<\operatorname{DoA}<\operatorname{DoAv}<100 \%$

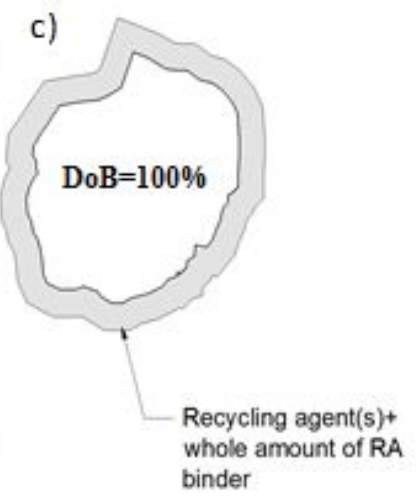

c) $\quad 0 \%<\mathrm{DoA}<\mathrm{DoAv}<100 \%$

Figure 5. Full-partial-null blending concepts including DoB, DoAv and DoA

\section{Conclusions and recommendations}

The results of a literature review indicate that despite the key concepts are clear, the blending of aged asphalt binder from reclaimed asphalt (RA) with a recycling agent is still misunderstood by the scientific community. Furthermore, there is a lack of clear definitions of the key quantities which creates confusion and overlapping. This clearly plays against the paramount shift towards recycled asphalt mixtures (RAM), hence on the basis of a critical review of the literature, this study provides the asphalt technologists with a comprehensive explanation of the blending phenomena with a nomenclature and a theoretical framework that, if validated, could improve mix design procedures for RAM as well as the classification of RA. For the latter, the framework considers the introduction of the Degree of binder Activity (DoA) as intrinsic property of the RA. DoA of selected RA could be assessed from laboratory technicians, asphalt contractor, material recyclers and would allow asphalt technologists having indications on the minimum amount of aged binder that could be considered active in a new asphalt mixture formulation. To introduce the blending phenomena in mix design procedures, the framework redefines the degree of binder Availability (DoAv) and the degree of blending (DoB) although provides 
a formulation only for the DoAv. In fact, the DoB is recognised to be still too complex to provide a specific formulation, hence a review of recent formulations of DoB and its relation with DoA and DoAv is provided to stimulate further investigations.

The framework clarifies key mechanisms and introduces several quantities, for which there are yet no overall accepted procedures for their determination. Thus new method(s) should be developed, or existing methods should be adapted. Due to the complex and heterogeneous nature of the RA, it is suggested that these methodologies should consider influencing parameters and should be verified through round robin campaign or inter-laboratory tests, including RA, mastics/mortar and possibly avoiding solvent extraction of the binders. Furthermore, since most of the research so far has been conducted at laboratory level, future works should consider linking the laboratory mix design with field trials. The scientific community and the asphalt industry are invited to validate the proposed framework and urged to working in this direction to finally classify RA and define mix design procedures including the effects of the blending phenomena.

\section{Nomenclature}

Absorbed RA binder: the amount of aged binder that is absorbed by RA aggregate and is not considered effective as binder film.

Activated RA binder: The activity of a certain amount of black rock RA binder and absorbed RA binder due to the combined effect of time, temperature and recycling agents.

Active RA binder: The amount of RA binder made active during processing of selected RA due to the effect of time and temperature. It consists of two components: liquid RA binder and Softer RA binder and it equals the available RA binder only when no recycling agent is included. 
Available RA binder: The amount of binder that can be considered available in the formulation of recycled asphalt mixtures. This is composed by the active RA binder, eventually complemented by the activated RA binder and the residual recycling agent.

Black rock RA binder: the amount of aged binder which has become so stiff and brittle that is considered as part of the RA aggregate, showing no change in physical-chemical behaviour and properties of itself.

Degree of binder Activity (DoA): An index indicating the minimum percentage of active RA binder that a designer can consider for a selected RA and a selected asphalt manufacturing process. DOA is an intrinsic property of each RA.

Degree of binder Availability (DoA): An index indicating the maximum percentage of available RA binder that a designer can consider in new mix design formulations.

Degree of binder Blending (DoB): An index describing to what extent the aged RA binder contributes to the final properties of the asphalt mixture's binder blend composed of aged binder and recycling agent.

Full availability (100\% active RA binder): the total amount of RA binder can be considered in the new mix design as part of the new binder blend.

Full blending: the available RA binder and the recycling agent blends perfectly, hence the property of the final binder blend/mixture are directly correlated to available RA binder.

Inactive RA binder: the amount of aged binder that can only be partially activated by the combined effect of time, temperature and a recycling agent.

Liquid RA binder: The portion of aged binder that moves from the RA particle to other 
RA particles, or virgin aggregates.

Long-term activated binder (LTAb): long term activity is due to an eventual diffusion of the recycling agent into the RA binder over time. It might result in an even bigger decrease of the unavailable RA binder.

Null availability/Black Rock ( $0 \%$ active RA binder): assumes that RA behaves as "black aggregate" and no RA binder can be considered in the new mix design as part of the new binder blend.

Null blending: available RA binder doesn't have any effects on the properties of the final binder blend/mix.

Partial blending: A more realistic hypothesis that lies between the full availability and black rock scenarios. Hence only a partial amount of RA binder can be considered in the new mix design as part of the new binder blend.

Partial blending: A more realistic hypothesis that lies between the full blending and null blending scenarios.

Recycling agents: the family of additives that are added within the recycled asphalt mixture manufacturing process to act on the aged binders with two different purposes: 1) "Rejuvenators", restore the properties of the aged RA binder (i.e. neat binder, naphthenic oils, etc.) and 2) "Lubricants", facilitate the mixing production process by allowing lower manufacturing temperatures, hence higher RA content (i.e. warm mix technologies).

Residual recycling agent: amount of remaining recycling agent that will stay in the blend as a residual component and maintaining the original properties .

Short-term activated binder (STAb): short term activity happens when the recycling 
agent gets in contact with aged binder at fixed processing conditions and it results in a decrease of the Black Rock and possibly Absorbed binder.

Softer RA binder: The layer of aged binder that does not move from the RA particles, but becomes softer and acts as a glue.

Total RA binder: amount of binder potentially available as binding agent and composed of the RA binder and, when present, recycling agents.

Unavailable RA binder: the amount of aged binder that cannot be considered available in a new formulation: This quantity is made of two components: Black Rock RA binder and Absorbed RA binder.

\section{References}

AASTHO M323-12: Standard Specification for Superpave Volumetric Mix Design. (2012).

Abd, D., Al-Khalid, H., \& Akhtar, R. (2018). Novel Methodology to Investigate and Obtain a Complete Blend between RAP and Virgin Materials. Journal of Materials in Civil Engineering, 30(5), 1-12. https://doi.org/10.1061/(ASCE)MT.19435533.0002230 .

Abed, A., Thom, N., \& Lo Presti, D. (2018). Design considerations of high RAPcontent asphalt produced at reduced temperatures. Materials and Structures/Materiaux et Constructions, 51(4), 1-16. https://doi.org/10.1617/s11527-018-1220-1

Al-Qadi, I., Carpenter, S., Roberts, G., Ozer, H., Aurangzeb, Q., Elseifi, M., \& Trepanier, J. (2009). Determination of Usable Residual Asphalt Binder in RAP. Retrieved from http://hdl.handle.net/2142/13714

Al-Qadi, I., Elseifi, M., \& Carpenter, S. (2007). Reclaimed Asphalt Pavement - A Literature Review. FHWA-ICT-07-001. 
AllBack2Pave. (2014). Retrieved January 1, 2017, from http://allback2pave.fehrl.org/

Ashtiani, M. Z., Mogawer, W. S., \& Austerman, A. J. (2018). A Mechanical Approach to Quantify Blending of Aged Binder from Recycled Materials in New Hot Mix Asphalt Mixtures. Transportation Research Record: Journal of the Transportation Research Board, 2672(28), 107-118. https://doi.org/10.1177/0361198118787634

ASTM 2172 - 17 - Standard Test Methods for Quantitative Extraction of Asphalt Binder from Asphalt Mixtures. (2017).

Booshehrian, A., Mogawer, W. S., \& Bonaquist, R. (2013). How to Construct an Asphalt Binder Master Curve and Assess the Degree of Blending between RAP and Virgin Binders. Journal of Materials in Civil Engineering, 25(12), 1813-1821. https://doi.org/10.1061/(ASCE)MT.1943-5533.0000726

Bowers, B. F., Huang, B., Shu, X., \& Miller, B. C. (2014). Investigation of Reclaimed Asphalt Pavement blending efficiency through GPC and FTIR. Construction and Building Materials, 50, 517-523. https://doi.org/10.1016/j.conbuildmat.2013.10.003

Bowers, B. F., Moore, J., Huang, B., \& Shu, X. (2014). Blending efficiency of reclaimed asphalt pavement: An approach utilizing rheological properties and molecular weight distributions. Fuel, 135, 63-68. https://doi.org/10.1016/j.fuel.2014.05.059

Bressi, S., Cavalli, M. C., Partl, M. N., Tebaldi, G., Dumont, A. G., \& Poulikakos, L. D. (2015). Particle clustering phenomena in hot asphalt mixtures with high content of reclaimed asphalt pavements. Construction and Building Materials, 100, 207-217. https://doi.org/10.1016/j.conbuildmat.2015.09.052

Campher, L. (2012). HERWONNE ASFALT : Hoe effektief is verouderde bitumen in Bitumen Stabiliserende Asfalt . Universiteit van Stellenbosch Departement.

Castorena, C., Pape, S., \& Mooney, C. (2016). Blending Measurements in Mixtures with Reclaimed Asphalt. Transportation Research Record: Journal of the Transportation Research Board, 2574, 57-63. https://doi.org/10.3141/2574-06

Cavalli, M. C., Griffa, M., Bressi, S., Partl, M. N., Tebaldi, G., \& Poulikakos, L. D. (2016). Multiscale imaging and characterization of the effect of mixing temperature on asphalt concrete containing recycled components. Journal of 
Microscopy, 264(1), 22-33. https://doi.org/10.1111/jmi.12412

Cavalli, M. C., Partl, M. N., \& Poulikakos, L. D. (2017). Measuring the binder film residues on black rock in mixtures with high amounts of reclaimed asphalt. Journal of Cleaner Production, 149, 665-672. https://doi.org/10.1016/j.jclepro.2017.02.055

Coffey, S., Dubois, E., Mehta, Y., Nolan, A., \& Purdy, C. (2013). Determining the impact of degree of blending and quality of reclaimed asphalt pavement on predicted pavement performance using pavement ME design. Construction and Building Materials, 48(November 2015), 473-478.

https://doi.org/10.1016/j.conbuildmat.2013.06.012

Coffey, S., Dubois, E., Mehta, Y., \& Purdy, C. (2013). Determine the Impact of Degree of Blending between Virgin and Reclaimed Asphalt Binder on Predicted Pavement Performance using Mechanistic-Empirical Design Guide (MEPDG). In Transportation Research Board (TRB) 92nd Annual Meeting. Washington, D.C. Copeland, A. (2011). Reclaimed Asphalt Pavement in Asphalt Mixtures: State of the Practice. Report No. FHWA-HRT-11-021. McLean. https://doi.org/10.1016/j.proeng.2016.06.119

COREPASOL. (2014). Retrieved January 1, 2017, from http://silnice.fsv.cvut.cz/corepasol/

Delfosse, F., Drouadaine, I., Largeaud, S., \& Dumont, S. F. (2016). Performance control of bituminous mixtures with a high RAP content. In K. Suchý, J. Valentin, M. Southern, C. Karcher, H. Odelius, J. P. Michaut, \& F. Cointe (Eds.), 6th Eurasphalt \& Eurobitume Congress. Prague, Czech Republic: Czech Technical University in Prague. https://doi.org/dx.doi.org/10.14311/EE.2016.050

Di Mino, G., Di Liberto, C. M., Noto, S., Wellner, F., Blasl, A., Airey, G., \& Lo Presti, D. (2015). AllBack2Pave AllBack2Pave End-User Manual. Retrieved from http://www.cedr.eu/download/other_public_files/research_programme/call_2012/r ecycling/allback2pave/AllBack2Pave_End-User-Manual.pdf

Ding, Y., Huang, B., \& Shu, X. (2016). Characterizing blending efficiency of plant produced asphalt paving mixtures containing high RAP. Construction and Building Materials, 126, 172-178. https://doi.org/10.1016/j.conbuildmat.2016.09.025 
Ding, Y., Huang, B., \& Shu, X. (2018). Blending efficiency evaluation of plant asphalt mixtures using fluorescence microscopy. Construction and Building Materials, 161, 461-467. https://doi.org/10.1016/j.conbuildmat.2017.11.138

Ding, Y., Huang, B., Shu, X., Zhang, Y., \& Woods, M. E. (2016). Use of molecular dynamics to investigate diffusion between virgin and aged asphalt binders. Fuel, 174(March), 267-273. https://doi.org/10.1016/j.fuel.2016.02.022

DIRECT-MAT. (2011). Retrieved January 1, 2017, from http://direct-mat.fehrl.org/

EARN. (2014). Retrieved January 1, 2017, from https://trl.co.uk/projects/effectsavailability-road-network-earn

EN 12697-1:2012 Bituminous mixtures - Test methods for hot mix asphalt - Part 1: Soluble binder content. (n.d.).

Gaitan, L., Mehta, Y., Nolan, A., Dubois, E., Coffey, S., McCarthy, L., \& Welker, A. (2013). Evaluation of the Degree of Blending and Polymer Degradation of Reclaimed Asphalt Pavement (RAP) for Warm Mix Asphalt. The Journal of Solid Waste Technology and Management, 39(2), 101-113. https://doi.org/10.5276/JSWTM.2013.101

Gottumukkala, B., Ph, D., Kusam, S. R., Tandon, V., \& Asce, A. M. (2018). Estimation of Blending of Rap Binder in a Recycled Asphalt Pavement Mix, 30(2), 1-8. https://doi.org/10.1061/(ASCE)MT.1943-5533.0002403.

Gundla, A., \& Underwood, S. (2015). Evaluation of in situ RAP binder interaction in asphalt mastics using micromechanical models. International Journal of Pavement Engineering, 18(9), 798-810. https://doi.org/10.1080/10298436.2015.1066003

Hajj, E., Salazar, L., \& Sebaaly, P. (2012). Methodologies for Estimating Effective Performance Grade of Asphalt Binders in Mixtures with High Recycled Asphalt Pavement Content. Transportation Research Record: Journal of the Transportation Research Board, 2294, 53-63. https://doi.org/10.3141/2294-06

He, Y., Alavi, Z., Harvey, J., \& Jones, D. (2016). Evaluating Diffusion and Aging Mechanisms in Blending of New and Age-Hardened Binders during Mixing and Paving. Transportation Research Record: Journal of the Transportation Research Board, (16), 64-73. https://doi.org/10.3141/2574-07

Hofko, B., Eberhardsteiner, L., Füssl, J., Grothe, H., Handle, F., Hospodka, M., ... 
Scarpas, A. (2016). Impact of maltene and asphaltene fraction on mechanical behavior and microstructure of bitumen. Materials and Structures, 49(3), 829-841. https://doi.org/10.1617/s11527-015-0541-6

Hossain, M., Musty, H. Y., \& Sabahfer, N. (2012). Use of High-Volume Reclaimed Asphalt Pavement (RAP) for Asphalt Pavement Rehabilitation Due to Increased Highway Truck Traffic from Freight Transportation. Retrieved from https://digitalcommons.unl.edu/matcreports/74/

Howard, I. L., Cooley, L. A., \& Doyle, J. (2009). Laboratory Testing and Economic Analysis of High RAP Warm Mixed Asphalt. Jackson, MS 39215-1850. Retrieved from https://rosap.ntl.bts.gov/view/dot/20311

Huang, B., Li, G., Vukosavljevic, D., Shu, X., \& Egan, B. (2005). Laboratory Investigation of Mixing Hot-Mix Asphalt with Reclaimed Asphalt Pavement. Transportation Research Record: Journal of the Transportation Research Board, 1929(Figure 1), 37-45. https://doi.org/10.3141/1929-05

Huang, S.-C., Pauli, A. T., Grimes, R. W., \& Turner, F. (2014). Ageing characteristics of RAP binder blends - what types of RAP binders are suitable for multiple recycling? Road Materials and Pavement Design, 15(sup1), 113-145. https://doi.org/10.1080/14680629.2014.926625

Jiang, Y., Gu, X., Zhou, Z., Ni, F., \& Dong, Q. (2018). Laboratory Observation and Evaluation of Asphalt Blends of Reclaimed Asphalt Pavement Binder with Virgin Binder using SEM/EDS. Transportation Research Record, 1-10. https://doi.org/10.1177/0361198118782023

Jiménez del Barco Carrión, A., Lo Presti, D., \& Airey, G. D. (2015). Binder design of high RAP content hot and warm asphalt mixture wearing courses. Road Materials and Pavement Design, 16(sup1), 460-474. https://doi.org/10.1080/14680629.2015.1029707

Kaseer, F., Arámbula-Mercado, E., \& Martin, A. E. (2019). A Method to Quantify Reclaimed Asphalt Pavement Binder Availability (Effective RAP Binder) in Recycled Asphalt Mixes. Transportation Research Record: Journal of the Transportation Research Board, 036119811882136. https://doi.org/10.1177/0361198118821366 
Kaseer, F., Garcia Cucalon, L., Arambula-Mercado, E., Epps Martin, A., \& Epps, J. (2018). Practical Tools for Optimizing Recycled Materials Content and Recycling Agent Dosage for Improved Short-and Long-Term Performance of Rejuvenated Asphalt Mixtures. In Association of Asphalt Paving Technologists. Jacksonville, Florida.

Kriz, P., Grant, D. L., Veloza, B. a., Gale, M. J., Blahey, A. G., Brownie, J. H., ... Maccarrone, S. (2014). Blending and diffusion of reclaimed asphalt pavement and virgin asphalt binders. Road Materials and Pavement Design, 15(sup1), 78-112. https://doi.org/10.1080/14680629.2014.927411

Liphardt, A., Radziszewski, P., \& Król, J. (2015). Binder blending estimation method in hot mix asphalt with reclaimed asphalt. Procedia Engineering, 111(TFoCE), 502509. https://doi.org/10.1016/j.proeng.2015.07.123

Lo Presti, D., Jimenez del Barco Carrion, A., Airey, G., \& Hajj, E. (2016). Towards $100 \%$ recycling of reclaimed asphalt in road surface courses: Binder design methodology and case studies. Journal of Cleaner Production, 131(May), 43-51. https://doi.org/10.1016/j.jclepro.2016.05.093

Lo Presti, D., Tebaldi, G., Kuna, K., Apeagyei, A., Grenfell, J., Airey, G., ... Jenkins, K. (2015). Evaluation of the Indirect Tensile Strength test to characterize Reclaimed Asphalt.

Lo Presti, D., Vasconcelos, K., Menegusso Pires, G., Jimenez Del Barco Carrion, A., Zaumanis, M., Orešković, M., ... Tebaldi, G. (2017). RILEM TC 264-RAP - Task Group 5 - Degree of Asphalt binder Activation. Retrieved May 10, 2018, from https://www.researchgate.net/project/RILEM-TC-RAP-Task-Group-5-Degree-ofasphalt-binder-activation

McDaniel, R. S., Soleymani, H., Anderson, R. M., Turner, P., \& Peterson, R. (2000). Recommended Use of Reclaimed Asphalt Pavement in the Superpave Mix Design Method. NCHRP Web Document 30 (Project D9-12). Transportation Reserach Board Of National Academics, Washington D.C. (Vol. 30). Retrieved from http://onlinepubs.trb.org/onlinepubs/nchrp/nchrp_w30-a.pdf

Mogawer, W., Bennert, T., Daniel, J. S., Bonaquist, R., Austerman, A., \& Booshehrian, A. (2012). Performance characteristics of plant produced high RAP mixtures. Road Materials and Pavement Design, 13(March 2015), 183-208. 
https://doi.org/10.1080/14680629.2012.657070

Mogawer, W., Booshehrian, A., Vahidi, S., \& Austerman, A. J. (2013). Evaluating the effect of rejuvenators on the degree of blending and performance of high RAP, RAS, and RAP/RAS mixtures. Road Materials and Pavement Design, 14(sup2), 193-213. https://doi.org/10.1080/14680629.2013.812836

Mollenhauer, K., De Bock, L., Olesen, E., Brosseaud, Y., Gaspar, L., McNally, C., ... Wik, O. (2010). Deliverable D5: Synthesis of national and international documents on existing knowledge regarding the recycling of reclaimed road materials in asphalt.

Nahar, S., Mohajeri, M., Schmets, A., Scarpas, A., van de Ven, M., \& Schitter, G. (2013). First Observation of Blending-Zone Morphology at Interface of Reclaimed Asphalt Binder and Virgin Bitumen. Transportation Research Record: Journal of the Transportation Research Board, 2370, 1-9. https://doi.org/10.3141/2370-01

Navaro, J., Bruneau, D., Drouadaine, I., Colin, J., Dony, A., \& Cournet, J. (2012). Observation and evaluation of the degree of blending of reclaimed asphalt concretes using microscopy image analysis. Construction and Building Materials, 37, 135-143. https://doi.org/10.1016/j.conbuildmat.2012.07.048

Newcomb, D. E., Ray Brown, E., \& Epps, J. A. (2007). Designing HMA mixtures with High RAP content: A practical guide, 41. Retrieved from www.asphaltpavement.org

Norton, A., Reger, D., DuBois, E., Kehr, D., Nolan, A., \& Mehta, Y. a. (2014). A Study to Evaluate Low Temperature Performance of Reclaimed Asphalt Pavement in Hot Mix Asphalt at Different Degrees of Blending. The Journal of Solid Waste Technology and Management, 39(4), 234-243. https://doi.org/10.5276/JSWTM.2013.234

Oliver, J. W. H. (2001). The Influence of the Binder in RAP on Recycled Asphalt Properties. Road Materials and Pavement Design, 2(3), 311-325. https://doi.org/10.1080/14680629.2001.9689906

Orešković, M., Bressi, S., Di Mino, G., \& Lo Presti, D. (2017). Influence of bio-based additives on RAP clustering and asphalt binder rheology. In A. Loizos, I. Al-Qadi, \& T. Scarpas (Eds.), Proceedings of Tenth International Conference on the 
Bearing Capacity of Roads, Railways and Airfields (pp. 1301-1306). Athens, Greece: CRC-Taylor \& Francis Group.

Partl, M. N., Bahia, H. U., Canestrari, F., Roche, C. de la, Benedetto, H. Di, Piber, H., \& Sybilski, D. (Eds.). (2013). Advances in Interlaboratory Testing and Evaluation of Bituminous Materials. Springer Netherlands. https://doi.org/10.1007/978-94007-5104-0

Rad, F., Sefidmazgi, N., \& Bahia, H. (2014). Application of Diffusion Mechanism. Degree of Blending Between Fresh and Recycled Asphalt Pavement Binder in Dynamic Shear Rheometer. Transportation Research Record: Journal of the Transportation Research Board, 2444(1), 71-77. https://doi.org/10.3141/2444-08

Re-Road. (2012). Retrieved January 1, 2017, from http://re-road.fehrl.org/

Rinaldini, E., Schuetz, P., Partl, M. N., Tebaldi, G., \& Poulikakos, L. D. (2014). Investigating the blending of reclaimed asphalt with virgin materials using rheology, electron microscopy and computer tomography. Composites Part B: Engineering, 67(March 2016), 579-587. https://doi.org/10.1016/j.compositesb.2014.07.025

Shirodkar, P., Mehta, Y., Nolan, A., Dubois, E., Reger, D., \& McCarthy, L. (2013). Development of blending chart for different degrees of blending of RAP binder and virgin binder. Resources, Conservation and Recycling, 73, 156-161. https://doi.org/10.1016/j.resconrec.2013.01.018

Shirodkar, P., Mehta, Y., Nolan, A., Sonpal, K., Norton, A., Tomlinson, C., ... Sauber, R. (2011). A study to determine the degree of partial blending of reclaimed asphalt pavement (RAP) binder for high RAP hot mix asphalt. Construction and Building Materials, 25(1), 150-155. https://doi.org/10.1016/j.conbuildmat.2010.06.045

Soleymani, H., Bahia, H., \& Bergan, A. (1999). Blending Charts Based on Performance-Graded Asphalt Binder Specification. Transportation Research Record, 1661(1), 7-14. https://doi.org/10.3141/1661-02

Stephens, J., Mahoney, J., \& Dippold, C. (2001). Determination of the PG binder grade to use in a RAP mix. Retrieved from https://rosap.ntl.bts.gov/view/dot/14366

Stimilli, A., Virgili, A., \& Canestrari, F. (2015). New method to estimate the "reactivated" binder amount in recycled hot-mix asphalt. Road Materials and 
Pavement Design, 16(sup1), 442-459.

https://doi.org/10.1080/14680629.2015.1029678

SUP\&R ITN. (2017). Retrieved January 1, 2017, from http://superitn.eu

Tebaldi, G., Dave, E. V., Cannone Falchetto, A., Hugener, M., Perraton, D., Grilli, A., ... Bocci, M. (2018). Recommendation of RILEM TC237-SIB: protocol for characterization of recycled asphalt (RA) materials for pavement applications. Materials and Structures/Materiaux et Constructions, 51(6). https://doi.org/10.1617/s11527-018-1253-5

Vassaux, S., Gaudefroy, V., Boulangé, L., Pevere, A., Michelet, A., Barragan-Montero, V., \& Mouillet, V. (2019). Assessment of the binder blending in bituminous mixtures based on the development of an innovative sustainable infrared imaging methodology. Journal of Cleaner Production, 215, 821-828. https://doi.org/https://doi.org/10.1016/j.jclepro.2019.01.105

Vassaux, S., Gaudefroy, V., Boulangé, L., Soro, L. J., Pévère, A., Michelet, A., ... Mouillet, V. (2018). Study of remobilization phenomena at reclaimed asphalt binder/virgin binder interphases for recycled asphalt mixtures using novel microscopic methodologies. Construction and Building Materials, 165, 846-858. https://doi.org/10.1016/j.conbuildmat.2018.01.055

Xu, J., Hao, P., Zhang, D., \& Yuan, G. (2018). Investigation of reclaimed asphalt pavement blending efficiency based on micro-mechanical properties of layered asphalt binders. Construction and Building Materials, 163, 390-401. https://doi.org/10.1016/j.conbuildmat.2017.12.030

Yu, S., Shen, S., Zhang, C., Zhang, W., \& Jia, X. (2017). Evaluation of the blending effectiveness of reclaimed asphalt pavement binder. Journal of Materials in Civil Engineering, 29(12), 1-8. https://doi.org/10.1061/(ASCE)MT.1943-5533.0002095.

Yu, S., Shen, S., Zhou, X., \& Li, X. (2018). Effect of Partial Blending on High Content Reclaimed Asphalt Pavement (RAP) Mix Design and Mixture Properties. Transportation Research Record: Journal of the Transportation Research Board, 2672(28), 79-87. https://doi.org/10.1177/0361198118780703

Zhang, K., Wen, H., \& Hobbs, A. (2015). Laboratory Tests and Numerical Simulations of Mixing Superheated Virgin Aggregate with Reclaimed Asphalt Pavement 
Materials. Transportation Research Record: Journal of the Transportation Research Board, 2506, 62-71. https://doi.org/10.3141/2506-07

Zhao, S., Huang, B., Shu, X., \& Woods, M. E. (2015). Quantitative Characterization of Binder Blending: How Much Recycled Binder Is Mobilized During Mixing? Transportation Research Record: Journal of the Transportation Research Board, 2506(2506), 72-80. https://doi.org/10.3141/2506-08

Zhao, S., Huang, B., Shu, X., \& Woods, M. E. (2016). Quantitative evaluation of blending and diffusion in high RAP and RAS mixtures. Materials and Design, 89, 1161-1170. https://doi.org/10.1016/j.matdes.2015.10.086 
Figure 1. Full-Partial-Null availability concept ...................................................6

Figure 2. Example of the RA binder components ................................................... 17

Figure 3. Schematic representation of the theoretical framework of the blending

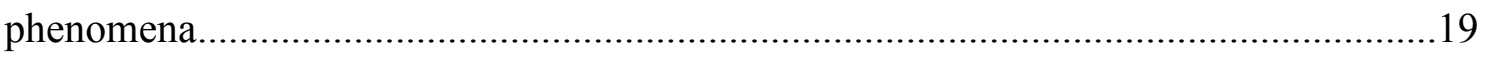

Figure 4. Blending chart and predicted law based on high PG temperature ...................25

Figure 5. Full-partial-null blending concepts including DoB, DoAv and DoA ............28 
Table 1. Definitions of terms related to the blending phenomena as found in literature ..8 Table 2. Influencing factors on the DoB: Design and manufacturing of asphalt mixture

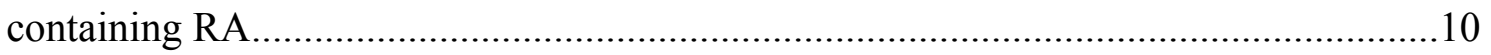

Table 3. Influencing factors on the DoB: RA characteristics....................................13

Table 4. Proposed formulas for determination of the DoB from investigated literature. 22 


\section{Detailed responses to reviewers}

\section{REVIEWER 1}

Thanks for submitting the paper on a very important subject for asphalt technology. I found the paper to be too long and covers way too much ground and would benefit from focussing on a subset of the work. In particular the references to recycling agents throughout the report don't really add anything to the understanding from my perspective. I was slightly confused by the whole DoB and DOA terminology and you do not explain what "activated" actually means? If something $\mathrm{s}$ activate does that mean it participates in the blend? If so what is the difference between the two terms. I appreciate tat you try to explain this but having been in the industry fro $30+$ years I have never used or seen either term before and don't really feel I understood the difference from your paper. I would challenge quite a few of your conclusions and still do not understand what the "framework" you refer to at the introduction and conclusions is? What is this exactly?

The paper has been significantly modified, restructured and shortened to cover only the explanation of the theoretical framework of the blending phenomena, through the results of a literature review on the DoB, DoAv and DoA. We hope that the additional effort to explain the framework and the introduction of a nomenclature provide a better experience to the reader.

\section{Detail comments by page and line}

Title - What is meant by "activation"?

A nomenclature was introduced to provide definitions and explanations

$1 / 8$ "wearing course" should read "surface course". This is prominent in the introduction but not throughout the more general discussion of the paper

Corrected

1/11 What "performance" are you referring to?

Corrected

$1 / 22$ What is the "framework" you refer to? 
The theoretical framework of the blending phenomena is defined in a specific paragraph and in a figure

$1 / 29$ What do you mean by "fundamental", there isn't anything fundamental presented in the paper?

Fundamental is here referred to the theoretical mechanisms and quantites that govern the blending phenomena

2/3 Is this about stockpiled materials? The term RA is used throughout, do you also mean RAP? RA is traditionally used to denote materials reclaimed at the plant

We use the term RA throughout the paper to indicate Recycled Asphalt (RA) materials family as indicated in European standards and other publications. We are aware of the widespread use of the RAP term and really have no preference neither a specific opinion on which is best. Recent publications of the RILEM community as well as European standards seems to move towards the RA term, hence this is used in this paper.

2/27 Is your Ireland reference correct? Are 100\% RA mixtures permitted? In which specification? No, it is not correct. This mistake is amended.

2/37 Is this just an issue for high RA content?

No. Corrected

2/54 Do you mean measuring (rather than predicting?)

No. Corrected accordingly

3/15 Are we in an era of $100 \%$ RAP????

The paragraph has been adapted, since We agree that most of our roads are not yet paved with surface made of $100 \%$ RAP. However, it is important to highlight that there is a lot going on with $100 \%$ RAP and results are already published (Zaumanis, M., Cavalli, M.C. \& Poulikakos, L. (2018) Design of 100\% RAP Hot-Mix Asphalt to Balance Rutting and Cracking performance, ISAP Conference, Fortaleza, Brazil; Zaumanis, M., Mallick, R. \& Frank, R. (2016) 100\% hot mix asphalt recycling: challenges and benefits, Transportation 
Research Procedia 14: 3493-3502; Lizarraga, J.M., Jimenez del Barco-Carrion, A., Ramirez, A., Diaz, P., Moreno-Navarro, F. \& Rubio, M.C. (2017) Mechanical performance assessment of half wam recycled asphalt mixes containing up to 100\% RAP. Materiales de Construcción 67 (327). There are also field experiences, one km of highway has just been constructed with $100 \%$ of recycled asphalt (https://www.usinenouvelle.com/article/eurovia-experimente-lepremier-enrobe-100-recycle-sur-une-autoroute.N753054, accessed on 12.10.2018.)

$3 / 36$ no need for the reference to recycling agent here

Corrected

3/75 what do you mean by "activated"?

A nomenclature was introduced to provide definitions and explanations

5/11 DoA = a decrease in weight of additional binder? Sorry I don't understand this point. $\mathrm{DoB}=$ the conventional (what are these?)/rheological properties of the blend?, really not clear to me from the paper

The paper has been significantly modified and restructured. We hope that both framework and nomenclature are now clear.

\section{5/34 Typo}

Corrected

6/43 restoring? restoring what?

It has been specified that these are rejuvenators which are here defined as those additive restoring the properties of the aged binder to the initial state.

$7 / 54$ you define this as an intrinsic property. This is not correct DoA is here introduced as an intrinsic property of a selected RA. We hope that explanation is now clear.

10/46 What is the "binder"??

The paper has been significantly modified and restructured. We hope that both framework and nomenclature are clear. 
$16 / 38$ if the mixture is $100 \%$ RA how can there be a degree of "blending"? How is MSCR useful? Doesn't explain

This section is not anymore included in this paper.

18/16 Can you really measure surface area and shape of RA?

This section is not anymore included in this paper.

21/56 Is E* really a measurement of performance? What about fatigue?

This section is not anymore included in this paper.

$23 / 27$ How can this be? $100 \%$ DoB at $10 \%$ addition and $24 \%$ at $80 \% ?$ ? needs to be explained further.

This section is not anymore included in this paper.

22/46 Unmobilized? Meaning?

This section is not anymore included in this paper.

29/45 Surely the SEM approach to film thickness is highly influence by compaction level and methodology as this dictates the aggregate spacing?

This section is not anymore included in this paper.

29/45 Mixing time? Even for black rock?

Corrected. Mixing time may have influence only on the available part of a recycled aged binder.

I would question the proposed "abrasion" effect. I do not agree with your aggregate shape conclusion. Is there really enough in the main body to make this a conclusion from this paper?

This conclusion was taken from the study performed by Zhao et al. (2015). There was stated that the shape of round-shaped gravel could affect the analysis.

$30 / 33$ What is the "framework" it isn't clear to me what you are referring to

The theoretical framework of the blending phenomena is defined in a specific paragraph and in a figure 
$42 / 8$ Here DoB is defined as the $\%$ that can be mobilized", this is different to the earlier defintion

A nomenclature was introduced to provide definitions and explanations

\section{REVIEWER 2}

good topic and exhaustive review, but more effort needs to be undertaken to present and organize the information in a more concise way with more subheadings and in summary tables or flow chart figures and bullet lists within text to break-up long paper good to recognize difference in $\mathrm{DoA}$ and $\mathrm{DoB}$ (and define up front in paper) and motivate research community to come together to define terms and recommend common characterization tests/methods/analyses

The paper has been significantly modified, restructured and shortened to cover only the explanation of the theoretical framework of the blending phenomena, through the results of a literature review on the DoB, DoAv and DoA. We hope that the additional effort to explain the framework and the introduction of a nomenclature make the reading experience better.

some parts unclear -

distinguish reactivated vs activated binder, A nomenclature was introduced to provide definitions and explanations

define absorber on p. 29, 
A nomenclature was introduced to provide definitions and explanations

confusing to include terms used in original papers and those defined in this paper in Table 4, A clear difference between the literature review and nomenclature was done. We hope that now it's cleares.

pre-processing conditions not well defined,

Fixed.

reliable grading curve not clear,

Fixed

decrease in weight for additional binder confusing,

Fixed.

formulation not clear on p. 9 ,

Fixed. Formulas and definitions have been adapted

asymptotic scenario not clear on p. 11 ("theoretical" instead?),

Fixed. Only "ideal" was used

recovered from small RA and large virgin aggregate on $\mathrm{p} .16$ sentence not clear

This section is not anymore included in the paper.

add 3.1 subheading,

This section is not anymore included in the paper.

define Black Rock phenomenon,

A nomenclature was introduced to provide definitions and explanations

move EDXS paragraph on p. 24

This section is not anymore included in the paper. 
be consistent with terms - factors vs parameters in section 4

A nomenclature was introduced to provide definitions and explanations

technical edit is also needed for preposition/word choice, consistency in terms, parallel structure, removal of first person, awkward terms (activations for example), etc.

The paper has been significantly modified and restructured. We hope that presentations is now improved. 
Figure 1. Full-Partial-Null avilability concept

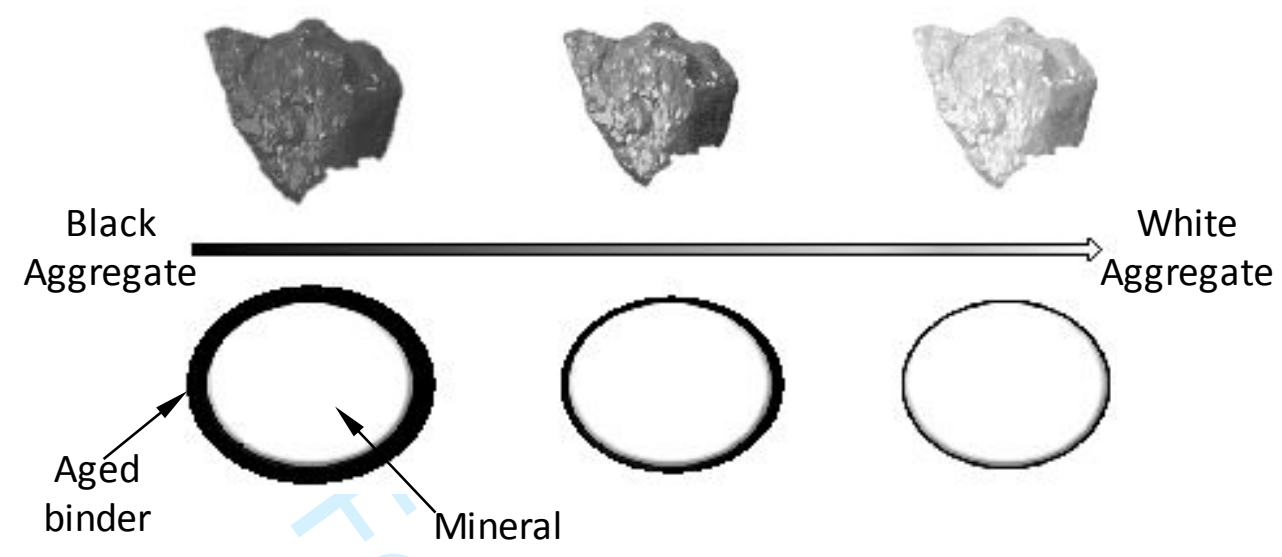

19

20

21 


$$
0
$$


Figure 3. Schematic representation of the theoretical framework of the blending phenomena

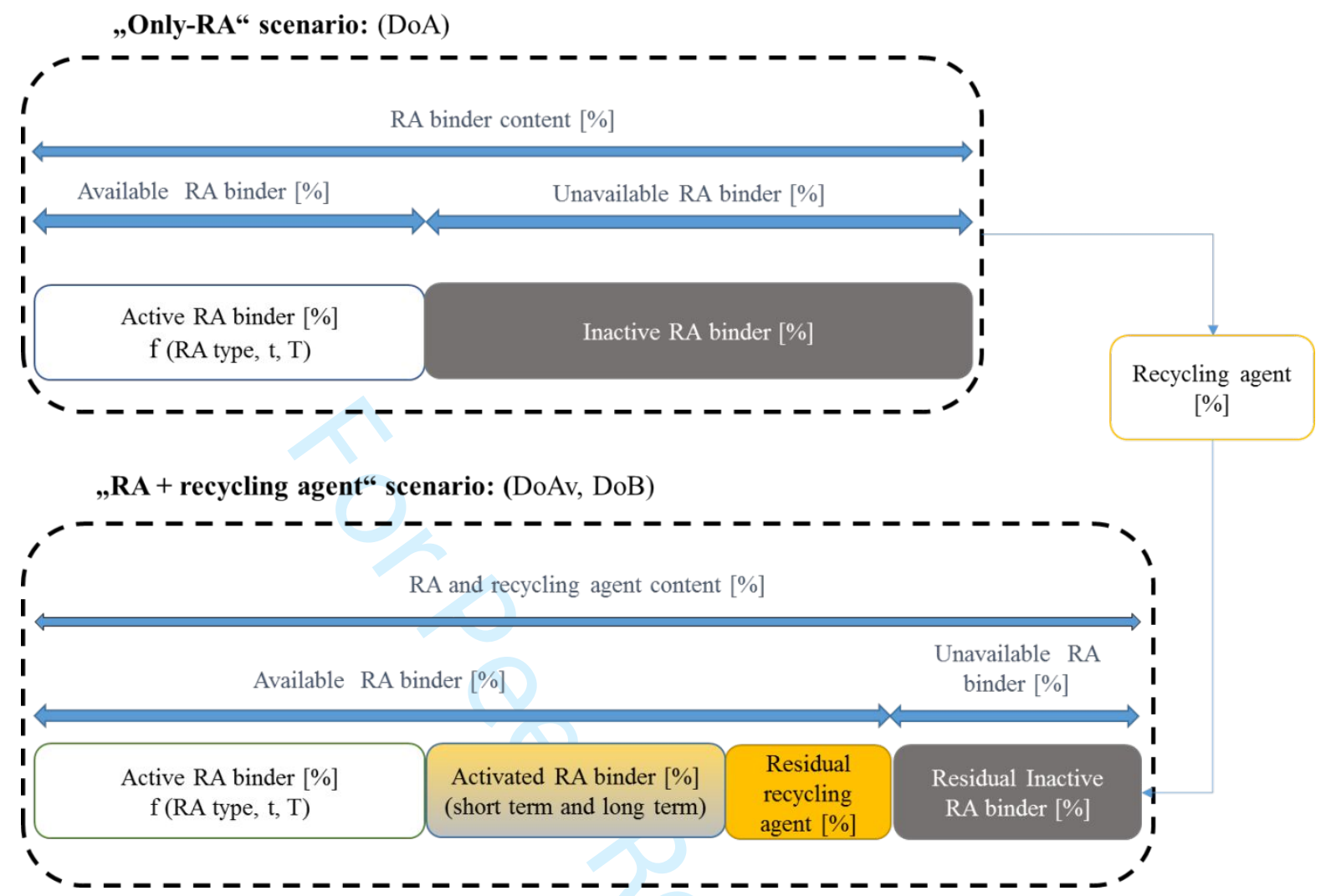


Figure 4. Blending chart and predicted law based on high PG temperature

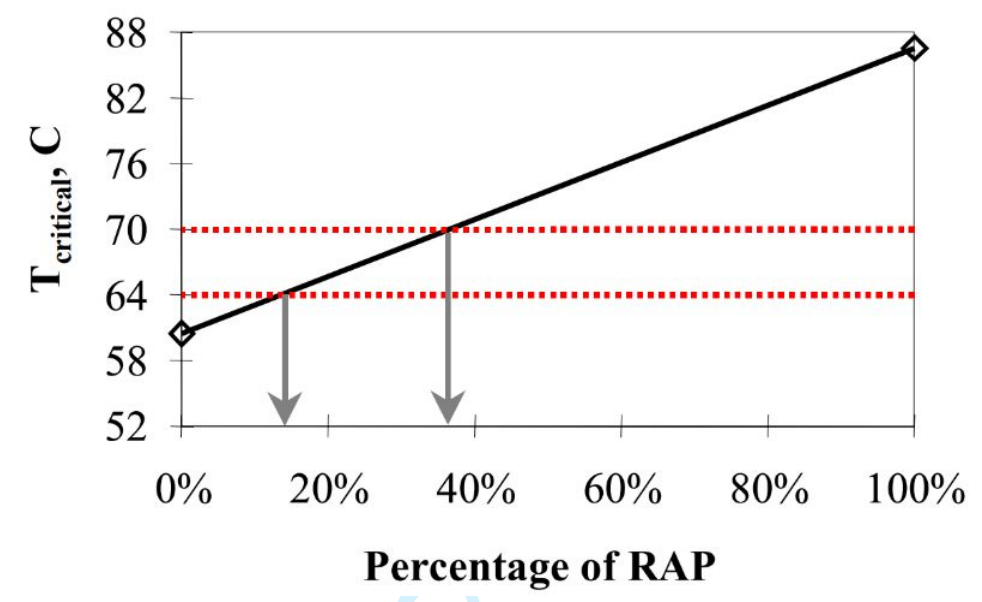


Figure 5. Full-partial-null blending concepts including DoB, DoAv and DoA

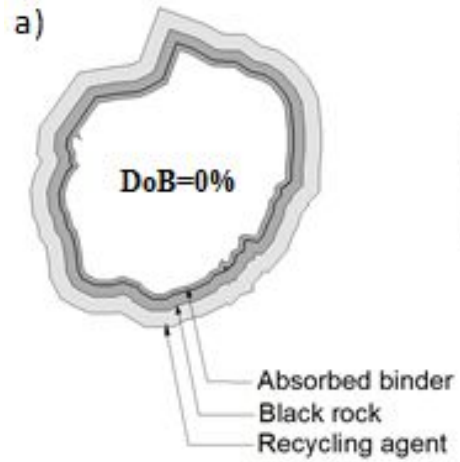

a) $\operatorname{DoA}=\operatorname{DoAv}=0 \%$

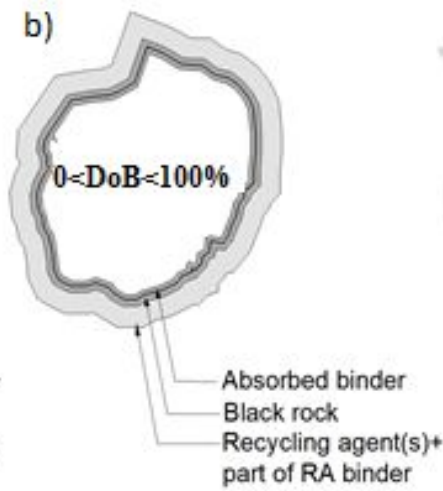

b) $\quad 0 \%<\operatorname{DoA}<\operatorname{DoAv}<100 \%$

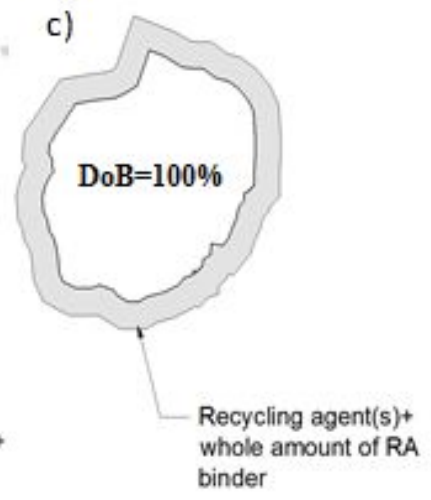

c) $\quad 0 \%<$ DoA $<$ DoAv $<100 \%$ 
Table 1. Definitions of terms related to the blending phenomena as found in literature

\begin{tabular}{ll}
\hline Reference & Definition \\
\hline (Shirodkar et al., 2011) & The degree of blending presents the amount of RAP \\
& binder that will be available for blending with virgin \\
& binder.
\end{tabular}

(Coffey, Dubois, Mehta, The degree of blending is the percentage of RA binder

Nolan, \& Purdy, 2013; that is effectively mobilized within the mix.

Coffey, Dubois, Mehta, \&

Purdy, 2013; Shirodkar et al.,

2013)

(Norton et al., 2014)

The amount of residual binder that is active in a mix is known as degree of blending.

(Stimilli et al., 2015)

Re-activated binder represents a partially melted aged binder that coats the RAP fraction and interacts with the virgin binder contributing to the overall performance of the resulting RMA.

(Gundla \& Underwood, Meso-blending refers to the blending of asphalt at 2015) scales above the micro- or molecular levels. It is less concerned with homogenization of the molecular constituents and more-so with the formation of a third binding material that may be considered homogeneous at the scale wherein rheological properties manifest (millimeters and smaller). It is at this scale that the 
asphalt binder imparts its rheological characteristics to the mixture.

(Ashtiani, Mogawer, \& Binder contribution describes the quantity of asphalt Austerman, 2018) binder from RAP that participates as effective binder in a mixture design.

(Vassaux et al., 2018)

The remobilization represents the ability for the virgin binder to make mobile again and disperse the RA aged binder layer.

(Gottumukkala, $\mathrm{Ph}$, Kusam, Blending ratio is defined as the ratio of the weight of Tandon, \& Asce, 2018) RAP binder blending with virgin binder to the total weight of RAP binder.

(Ding et al., 2018)

The mobilization rate is defined as the percentage of RA binder that can be mobilized during mixing, peeled off RA aggregate and made available for blending with recycling agents.

(Vassaux et al., 2019)

"Blend" presents the ability of two components to create a homogenous product where the chemical composition is identical everywhere at the scale observation of the study. 
Table 2. Influencing factors on the DoB: Design and manufacturing of asphalt mixture containing RA

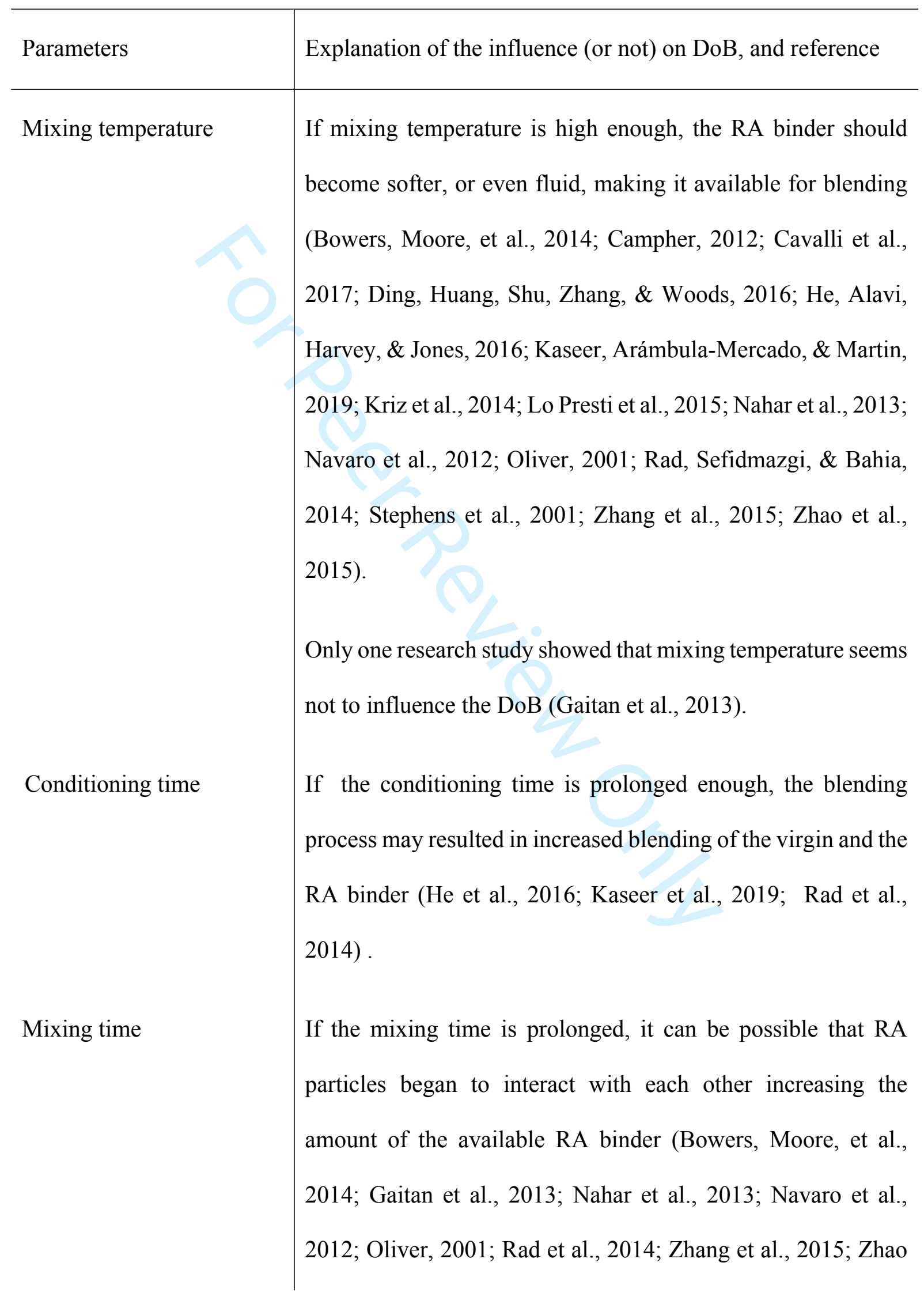


et al., 2016).

Only one research study showed that this is not the case (Stephens et al., 2001).

Content of RA in a new mixture

Virgin aggregate shape

Binder additives and admixtures

Virgin binder properties
Several studies showed that if the RA content is too high, more energy would be required to activate the RA binder (Booshehrian et al., 2013; Gottumukkala et al., 2018; Huang, Pauli, Grimes, \& Turner, 2014; Kriz et al., 2014; McDaniel, Soleymani, Anderson, Turner, \& Peterson, 2000; Oliver, 2001; Shirodkar et al., 2011; Stimilli et al., 2015; Zhang et al., 2015; Zhao et al., 2015).

However, one study showed that RA content does not influence the amount of active binder (B. Huang, Li, Vukosavljevic, Shu, \& Egan, 2005).

When virgin aggregate grains have high angularity, it will be easier to release the aged binder from the RA particles compared to more rounded aggregate (Zhao et al., 2015).

Recycling agents, anti-stripping agents or other additives may be mixed with the RA or added to the virgin binder with the aim to soften or activate the RA binder (Bowers, Moore, et al., 2014; Gaitan et al., 2013; Kaseer et al., 2019; Liphardt et al., 2015; Mogawer et al., 2013)

If the virgin binder has lower viscosity, it will easily cover RA 
particles and improve the DoB (Booshehrian et al., 2013;

Gottumukkala et al., 2018; Hofko et al., 2016; Nahar et al., 2013; Norton et al., 2014; Rad et al., 2014; Shirodkar et al., 2013, 2011).

This does not seem the case for the research study conducted by Huang et al. (2014).

Filler particles

Aggregate absorption

Mixture reheating

Surface texture of virgin aggregate

Virgin aggregate (type, No influence (Orešković et al., 2017; Stephens et al., 2001)

High amount of filler particles will absorb a recycling agent before it covers RA and starts with softening of the available recycled aged binder (Al-Qadi et al., 2009; Stimilli et al., 2015)

Aggregate with high porosity will absorb a recycling agent decreasing the active amount of recycling agent that is considered during mix design phase (Al-Qadi et al., 2009).

Successive heating of asphalt mixtures containing RA can increase the diffusion process improving the DoB (Booshehrian et al., 2013).

Recycling agent can fulfil convex parts of the grains before blending with the RA binder decreasing the designed amount of a recycling agent (Cavalli et al., 2016, 2017). source, fraction size) 
Table 3. Influencing factors on the DoB: RA characteristics

\begin{tabular}{|c|c|}
\hline Parameters & Explanation of the influence (or not) on DoB, and reference \\
\hline $\begin{array}{l}\text { RA Conditioning time / } \\
\text { temperature }\end{array}$ & $\begin{array}{l}\text { Conditioning the RA for prolonged time, at high operative } \\
\text { temperatures seems to be beneficial for softening the RA binder } \\
\text { (He et al., 2016; Rad et al., 2014). }\end{array}$ \\
\hline & $\begin{array}{l}\text { One research study showed that this is not the case (Gaitan et } \\
\text { al., 2013). }\end{array}$ \\
\hline RA binder properties & $\begin{array}{l}\text { With the increase of the RA binder stiffness, it will be more } \\
\text { difficult to increase the DoB (Booshehrian et al., 2013; Hofko } \\
\text { et al., 2016; Kaseer et al., 2019; Nahar et al., 2013; Norton et } \\
\text { al., 2014; Rad et al., 2014; Shirodkar et al., 2013, 2011). } \\
\text { This does not seem the case for one research studies (S.-C. } \\
\text { Huang et al., 2014). }\end{array}$ \\
\hline RA binder film thickness & $\begin{array}{l}\text { As much as the RA binder film is thicker, there will be more } \\
\text { binder which may be activated and blended during the mixing } \\
\text { phase increasing the DoB (Cavalli et al., 2016, 2017; Kriz et } \\
\text { al., 2014; Liphardt et al., 2015; Stimilli et al., 2015). }\end{array}$ \\
\hline RA fraction size & $\begin{array}{l}\text { Due to increase of the specific surface area with reduction in } \\
\text { the size of RA particles, the amount of aged binder will be } \\
\text { higher implying more binder available for blending (Castorena }\end{array}$ \\
\hline
\end{tabular}


et al., 2016; Ding, Huang, \& Shu, 2016; Stephens et al., 2001; Stimilli et al., 2015).

However, this does not seem the case for Shirodkar et al. (2011)

\section{RA Variability}

\section{Moisture content of RA}

Surface texture and the micro geometrical inhomogeneity of RA aggregate
Since the mixing time is limited during asphalt production phase, heating of the RA with high moisture content will firstly cause the release of water, not softening of the RA binder (Campher, 2012; Zhang et al., 2015).

High RA variability can contribute an unequal distribution of both RA binder and aggregated causing various DoB within an asphalt mixture (Cavalli et al., 2016; Norton et al., 2014).

If the RA aggregate is geometrically inhomogeneous, the RA binder will be trapped in convex parts of grains and possible would not be able to be released during mixing phase (Cavalli et al., 2016, 2017) 
Table 4. Proposed formulas for determination of the DoB from investigated literature

Reference Formula

(Shirodkar et al., Blending ratio $=\frac{\mid A\left(\text { virgin }_{\text {agg }}\right)_{\text {blend binder }}-A\left(R A P_{\text {agg }}\right)_{\text {blend binder }} \mid}{\left|A_{\text {virg gin binder }}-A_{\text {RAP virgin binder oblend }}\right|}$ Equation 1 2011)

where $A\left(\text { virgin }_{\text {agg }}\right)_{\text {blend binder }}$ is binder property " $\mathrm{A}$ " of blended binder coating the virgin aggregate, $A\left(R A P_{\text {agg }}\right)_{\text {blend binder }}$ is binder property "A" of binder blend coating the RAP aggregate, $A_{\text {virgin binder }}$ binder property "A" of virgin binder and $A_{R A P}$ virgin binder 0 blend is binder property " $\mathrm{A}$ " of the RA and virgin binder that is coating the RA aggregate assuming $0 \%$ blending. Degree of parital blending $(\%)=100 \mid 1-$ Blending ratio $\mid$ Equation 2

(Bowers, Moore, Blending ratio $=\frac{\text { Coarse } L M S \%}{\text { Fine } L M S \%}$ Equation 3 et al., 2014) where Coarse $\mathrm{LMS} \%$ presents the $\mathrm{LMS} \%$ of the coarse aggregate and Fine LMS\% presents the LMS\% of fine aggregate. LMS\% is defined by the area beneath the chromatogram obtained by using Gel Permeation Chromatography (GPC). When dividing the chromatogram into 13 slices, the first 5 are considered the LMS and can be expressed as following:

$$
L M S \%=\frac{\text { Area of first } \frac{5}{13} \text { of chromatogram }}{\text { Total Ared beneath chromatogram }} \times 100 \quad \text { Equation } 4
$$

(Kaseer, Garcia $P G H_{\text {blend }}=\left(R A P_{B R} \times P G H_{R A P}\right)+\left(R A S_{B R} \times P G H_{R A S}\right)+\left(B_{B R} \times\right.$ Cucalon, $\left.P G H_{\text {Base }}\right) \quad$ Equation 5

Arambulawhere $\mathrm{PGH}_{\text {blend }}$ is the high $\mathrm{PG}$ temperature of binder blend, $\mathrm{RAP}_{\mathrm{BR}}$ 
Mercado, Epps is RA binder ratio, $\mathrm{PGH}_{\mathrm{RAP}}$ is high $\mathrm{PG}$ temperature of RA binder, Martin, \& Epps, RAS $_{\mathrm{BR}}$ is RAS ratio (if used), $\mathrm{PGH}_{\mathrm{RAS}}$ is high $\mathrm{PG}$ temperature of 2018) RAS (if used), $\mathrm{B}_{\mathrm{BR}}$ is virgin binder ratio and $\mathrm{PGH}_{\mathrm{Base}}$ is high $\mathrm{PG}$ temperature of virgin binder.

(Yu, Shen, Zhang, $\quad B R=\frac{\ln \left(R_{c}^{\prime}\right)-\ln \left(R_{v}\right)}{\ln \left(R_{p}\right)-\ln \left(R_{v}\right)} x 100 \%$

Equation 6

Zhang, \& Jia, Where BR presents the RAP blending ratio, $R^{\prime}{ }_{c}$ presents specific 2017; Shuai $\mathrm{Yu}$, property parameters for a coarse-mixture binder, $R_{v}$ is specific Shen, Zhou, \& Li, $\quad$ binder property parameters for the virgin binder and $R_{p}$ is specific 2018) binder property parameters for the proportion binder.

(Abed, Thom, \& DoB\% $=\frac{I T S M_{A C-50 \% R A P}}{I T S M_{\text {control }}} \times 100 \%$ Equation 7

Lo Presti, 2018)

Where $\mathrm{DoB} \%$ is the percentage of the degree of blending between RAP and soft binders, ITSM $A C-50 \% R A P$ is the stiffness modulus of AC samples with $50 \%$ of RAP and ITSM $M_{\text {control }}$ is the stiffness of the control mixture. 